\title{
MicroRNA miR-24-3p Mediates the Negative Regulation of Lipopolysaccharide-Induced Endometrial Inflammatory Response by Targeting TNF Receptor-Associated Factor 6 (TRAF6)
}

\author{
Ayodele Olaolu Oladejo (1D ${ }^{1,2}$, Yajuan $\mathrm{Li}^{\prime}$, Bereket Habte Imam (D) ${ }^{1,3}$, Xiaoyu Ma', Wenxiang Shen ', \\ Xiaohu Wu $\oplus^{\prime}$, Wei Jiang', Jie Yang', Yanan Lv', Xuezhi Ding', Shengyi Wang $\oplus^{\prime}$, Zuoting Yan' \\ 'Key Laboratory of Veterinary Pharmaceutical Development of Ministry of Agriculture, Lanzhou Institute of Husbandry and Pharmaceutical Sciences of \\ Chinese Academy of Agricultural Science, Lanzhou, 730050, People's Republic of China; ${ }^{2}$ Department of Animal Health Technology, Oyo State College of \\ Agriculture and Technology, Igboora, 20I 103, Nigeria; ${ }^{3}$ Department of Veterinary Science, Hamelmalo Agricultural College, Keren, 397, Eritrea
}

Correspondence: Zuoting Yan, Key Laboratory of Veterinary Pharmaceutical Development of Ministry of Agriculture, Lanzhou Institute of Husbandry and Pharmaceutical Sciences of Chinese Academy of Agricultural Science, Lanzhou, 730050, People's Republic of China, Tel +86 I39190672I5, Email yanzuoting@caas.cn

Purpose: Endometritis is a female reproductive disease that affects the cattle industries development and microRNAs (miRNAs) play a pivotal role and critical regulators of the innate immune response in varieties of diseases. The present study intends to investigate the regulatory role of miR-24-3p in the innate immune response involved in endometritis and evaluate its therapeutic potential.

Methods: Whole mice uteri and bovine endometrial epithelial cells (BEECs) were separately stimulated with LPS. The BEECs were also transfected with miR-24-3p mimic and negative control; siTRAF6 and siNC; pcDNA3.1 empty and pcDNA3.1(+)TRAF6 separately with LPS stimulation. The expression levels of miR-24-3p and TRAF6 were measured via quantitative real-time polymerase chain reaction (qRT-PCR) and Western blot, respectively. LPS-induced inflammatory response assessed by inflammatory cytokines secretion and expression via ELISA and qRT-PCR. Bioinformatics analysis and luciferase reporter assay validated the interaction between miR-24-3p and TRAF6. The activation of the NF-кB/MAPK pathway and p65 phosphorylation was investigated by Western blot and immunofluorescence assay, respectively.

Results: The expression of miR-24-3p was decreased, and TRAF6 was elevated with an increased level of pro-inflammatory cytokines in LPS-treated BEECs and mice uterus. The overexpression of miR-24-3p suppressed LPS-induced secretion of inflammatory cytokines (IL-1 $\beta$, IL-6, IL-8 and TNF- $\alpha$ ) and deactivation of NF-KB/MAPK pathways. The downregulation of TRAF6 inhibited LPS-induced inflammatory response in BEECs. TRAF6 is validated as a target of miR-24-3p, and miR-24-3p reversed the overexpression of cloned TRAF6 on inflammation response in BEECs.

Conclusion: Our findings demonstrate that the overexpression of miR-24-3p attenuates endometrial inflammation and the expression of pro-inflammatory mediators via suppressing TRAF6. Therefore, modulating the pathogenesis of endometritis and possibly, a therapeutic potential against endometritis.

Keywords: endometritis, miR-24-3p, TRAF6, NF-кB/MAPK, inflammation

\section{Introduction}

A healthy uterine environment is essential for successful dairy herd reproduction. The innermost part of the uterus is the endometrium. $^{1,2}$ The anato-physiological position and features of the endometrium supported its susceptibility to postpartum invasion by an opportunistic microorganism, thereby leading to inflammatory response and prolonged invasion leading to severe disruption in the anatomical architecture of the endometrium. ${ }^{2-4}$ Endometritis is the most frequent disease that causes decreased milk production, abortion, and infertility in humans and livestock. ${ }^{4}{ }^{6}$ Researchers have reported the incidence of postpartum Endometritis between $37 \%$ and $74 \%$ of cows, ${ }^{2,4,5}$ which implies a substantial economic loss in the cattle industry. Escherichia 
coli $(E$. coli $)$ is a significant pathogen isolated from the uterine lumen, and it is the most common pathogenic flora in the first few days after birth. ${ }^{6}$ The endotoxin in Gram-negative bacteria cell walls is lipopolysaccharide (LPS). ${ }^{7-9}$ It is significant in developing inflammatory symptoms. The LPS can activate the host's innate immune response due to invading pathogens through several cellular receptors, including Toll-like receptors (TLRs) that recognize specific pathogen-associated molecular patterns (PAMPs) ${ }^{8,10}$ The activation of these cellular receptors usually triggered different signaling pathways in endometrial inflammation. Toll-like receptors (TLRs) recognize and respond to pathogen-associated molecular patterns and endogenous signals associated with danger. ${ }^{10,11}$ TLRs stimulate homotypic recruitment of one or more proteins from a family of five cytosolic. TIR-containing adaptor proteins respond to ligand-induced dimerization via their cytosolic Toll/IL-1 receptor (TIR) domain. ${ }^{10-13}$ All TLRs, except for TLR3, recruit $M y D 88$ to their receptor complex, as do the IL-1 receptor family members. ${ }^{8}$ MyD88 recruits interleukin-1 receptor-associated kinase 1 (IRAK1), IRAK4, and then TNF receptor-associated factor 6 (TRAF6), which results in the nuclear translocation of the prototypic inflammatory transcription factor NF-KB, termed the canonical pathway, ${ }^{11-14}$ which encodes inflammatory genes such as TNF-, IL-1 $\beta$, IL-6, and IL-8. Although TLRs induce common signaling pathways, there is specificity in the recruitment of TIR-containing adapter proteins. ${ }^{11,12}$ TNF receptor-associated factor 6 (TRAF6) was majorly describing an adapter capable of mediating NF-KB and MAPK activation. TRAF6 is one of seven closely related TRAF proteins, which are adapter proteins linking the TNF receptor (TNFR) superfamily to intracellular signaling transmission. ${ }^{11,13-15}$ TRAF6 is a pivotal signaling adaptor protein in developing several tissues, including mammary glands, uterine tissue, lymph nodes, skin, and the central nervous system. ${ }^{16}$ It is also crucial in regulating many physiological processes, including innate immunity, adaptive immunity, inflammation, and cellular metabolism. ${ }^{17-20}$ TRAF6is required to activate an NF$\kappa \mathrm{B}$ inducing kinase (NIK)-dependent IKK $\alpha$-RelB (p65)-p52 pathway. ${ }^{19-23} \mathrm{NF}-\mathrm{kB}$ pathways can affect the activation of the MAPK pathways in the inflammatory response. ${ }^{22,23}$ MAPK is a kinase family, including $\mathrm{p} 38$, JNK, and ERK protein substrates. ${ }^{24-26}$ MAPK pathway is preferentially activated in response to various types of cellular stresses, immune and inflammatory responses. ${ }^{26-28}$ TRAF6 is involved in activating p38, ERK1, and JNK through multiple MAP3Ks. ${ }^{24,28,29}$

MicroRNAs (miRNAs) have recently been revealed as a specific subset of gene regulators that play critical roles in normal cell function and disease development, including the pathophysiology of uterine and cardiovascular diseases, cancer, and inflammation. ${ }^{30-33}$ MiRNAs are non-coding RNAs with a length of 19-24 nucleotides that operate as posttranscriptional repressors of gene expression by interfering with the translation or stability of target mRNA and affecting a massive spectrum of genes. ${ }^{31-33}$ MiRNAs are a new class of biomarkers and therapeutic targets since they regulate immune function and inflammation. ${ }^{30,32}$ A series of research evidence shows that miR-24-3p was implicated in different infectious diseases, disorders, and inflammation. ${ }^{34-38} \mathrm{Hu}$ et al ${ }^{34}$ reported that bta-miR-24-3p inhibits proliferation and promotes myogenic differentiation of progenitor cells in Fetal Bovine Skeletal Muscle. MiR-24-3p protects against myocardial ischemia and reperfusion injury by being a cardioprotective factor. ${ }^{35}$ MiR-24 inhibits the proliferation and migration of vascular endothelial cells by deactivating the NF-KB signaling pathway, regulating inflammation in endothelial cells, and preventing the NF-KB signaling pathway in atherosclerosis. ${ }^{36}$ In LPS-challenged neonatal rats, miR-24 overexpression reduced lung inflammation ${ }^{37}$ and disrupted the inflammatory pathway. ${ }^{38}$ Zhao et al revealed that miR-643 inhibits the LPS-induced inflammatory response by targeting TRAF6 and down-regulating TRAF6 in endometrial epithelial cells. ${ }^{39}$ Bta-miR-146a inhibited the mRNA and protein expression levels of the TRAF6 gene as it served an anti-inflammatory function. ${ }^{40}$ It acted as a negative feedback regulator of bovine inflammation and innate immunity through downregulation of the TLR4/NF- $\mathrm{KB}$ pathway in LPS-stimulated bovine mammary epithelial cells. ${ }^{41}$ MiR-146a represses TNF receptor-associated factor 6 (TRAF6), an innate and adaptive immunity element that activates the NF- $\mathrm{BB}$ pathway. ${ }^{42}$

However, the underlying mechanism of TRAF6 resulting in endometrial destruction and the severity of endometrium inflammation are questionable. The potential biomarker and baseline therapeutic development against Endometritis is still poorly understood. In this research, we investigated the expression of TRAF6 in the endometrium and the roles of TRAF6 in BEEC's proliferation and immuno-inflammatory effects. Based on these findings, we hypothesized that BEECs transfected with bta-miR-24-3p could overexpress bta-miR-24-3p to attenuate experimental Endometritis by targeting TRAF6 expression through NF-KB/MAPK signaling pathways. The research flow chart is indicated in Supplementary Figure 1. 


\section{Materials and Methods}

\section{Isolation and Culture of Primary Bovine Endometrial Epithelial Cells (BEECs)}

Our laboratory isolated bovine endometrial epithelial cells (BEECs) from healthy dairy cows' uterine tissues. ${ }^{43}$ Briefly, the uteri are brought to the laboratory in a sterile PBS(P1020. Solarbio, Beijing, China) (pH 7.2) containing penicillin $(100 \mathrm{mg} / \mathrm{mL})$ and streptomycin $(100 \mathrm{U} / \mathrm{mL})$ from a local slaughter slab. Endometrium from the uterine horn was incised into $2-3 \mathrm{~cm}$ smaller pieces, washed in PBS ( $\mathrm{pH} 7.2$ ) twice. Then uterine tissue was digested with $1 \%$ collagenase I (C4361,Sigma, USA) with DMEM/F12 dilution (SH30069.04,HyClone, USA) for 6hours. The digested endometrium was scraped using a sterile cell scraper, scraped materials were collected and washed in PBS (pH 7.2). The digested endometrium molecules were centrifuged at $1000 \mathrm{~g}$ for $5 \mathrm{~min}$ to collect the cell suspension. Subsequently, cells were cultured in DMEM/F12 with 10\% fetal bovine serum (A3161001, Gibco, Australia), penicillin (100 mg/mL), and streptomycin $(100 \mathrm{U} / \mathrm{mL})$ at $37^{\circ} \mathrm{C}$ with $5 \% \mathrm{CO}_{2}$ and $95 \%$ sterile air when the viability $>95 \%$. The medium was changed within 48 hours intervals until the cells reached approximately $80 \%$ confluence. Some cells were cryopreserved at $-80^{\circ} \mathrm{C}$ for before practical usage.

\section{Experimental Endometritis Models}

All animal experiments in this research were performed according to NIH guidelines and approved by the Institutional Animal Care and Use Committee of Lanzhou Institute of Husbandry and Pharmaceutical Sciences of the Chinese Academy of Agricultural Sciences (SYXK-2014-0002). The study used mature Kunming female mice, 50-60g in weight and 10 weeks old, obtained from the Lanzhou Institute of Husbandry and Pharmaceutical Sciences' center for rearing laboratory animals. The animals were kept in standard cages at a temperature of $25^{\circ} \mathrm{C}$ with a 12-hour light-dark cycle and free access to food and clean water. The mice were randomly divided into a control group and an LPS group, with ten mice in each group. As mentioned earlier, a mouse endometritis model was established. Mice were perfused with LPS (L2630, E.coli 0111:B4 5, 2mg/ kg), and mice in the control group received an equal amount of phosphate-buffered saline (PBS). After 24 hours, the mice were euthanized using cervical dislocation. Blood and uterine tissues were obtained for further analysis. Six mice were used for the evaluation of histopathological changes per group. Tissues from the remaining mice were harvested for RNA and protein extraction.

Bovine endometrial epithelial cells (BEECs) were cultured. They are passage in DMEM supplemented with 10\% FBS at $37^{\circ} \mathrm{C}$ in a humidified atmosphere with $5 \% \mathrm{CO} 2$ and later treated with LPS of $3 \mu \mathrm{g} / \mathrm{mL}$ diluted by DMEM without FBS. The cell density was adjusted to $2 \times 10^{5}$ cells/well. The cells were cultured in the 6-well plate for 24 hours; the supernatant was then exchanged, replaced with new DMEM and 10\% FBS, and cultured for an additional 24hours. Each group was conducted in triplicates. The experimental cells were collected for further processing.

\section{Histopathological Examinations}

Small segments of uterine tissues were fixed with $4 \%$ paraformaldehyde for 24 hours at room temperature and then embedded in paraffin, serially sectioned at the 4-um thickness, and stained with hematoxylin and eosin (H\&E) for morphological evaluation.

\section{Cell Proliferation Assay}

Cell proliferation was examined using a cell counting kit-8 (CCK-8) assay kit (C0037, Beyotimes, Shanghai, China). The BEECs $\left(5 \times 10^{4}\right.$ cells/well) were plated in 96 -well plates and incubated at $37{ }^{\circ} \mathrm{C}$ for 24 hours; the culture media was removed, and the cells were treated with $3 \mu \mathrm{g} / \mathrm{mL}$ LPS, bta-miR-24-3pmimic, bta-miR-24-3pmimic negative control, with each group having five replicates with controlled incubation for 7hours. After, the cells were incubated with $10 \mu \mathrm{L}$ of CCK-8 solution for 4 hours at $37{ }^{\circ} \mathrm{C}$, and the absorbance was read at $450 \mathrm{~nm}$ using a microplate reader (Bio-Rad Instruments, Hercules, CA, United States). 


\section{Cell Transfection of bta-miR-24-3p and Knockdown of TRAF6 Experiment}

The bta-miR-24-3p mimic, negative control, Si-TRAF6, and si-Negative control were synthesized by GenePharma (Shanghai, China). The BEECs were equally distributed at $2 \times 10^{5}$ cells $/ \mathrm{mL}$ density into 6 -well plates (Corning Inc, Corning, NY, United States). When the confluence reached $70 \%$ during incubation, cells were transfected with the btamiR-24-3p mimic, negative control, Si-TRAF6, si-negative control with GP transfect mate (A10003, GenePharma, Shanghai, China) according to the manufacturer's instructions, and $3 \mu \mathrm{g} / \mathrm{mL}$ LPS was added to the required plates for 24hours. All the experiments were done in triplicates, and transfection efficiency was measured by qPCR assay and Western blot (WB) after cell transfection. These sequences are shown in Table 1.

\section{Recombinant Plasmid Construction and Transfection}

The recombinant plasmid pcDNA3.1(+)TRAF6 was digested by $\mathrm{KpnI}$ and $\mathrm{XhoI}$ at $37^{\circ} \mathrm{C}$ overnight. The TRAF6-encoding gene was segregated, reclaimed, and depurated. Then the depurant products were ligated with pcDNA3.1(+) by $5 \mu \mathrm{L}$ TRAF6 DNA ligase (GeneCreate, Wuhan, China) at a ratio of $3: 1$ at $4^{\circ} \mathrm{C}$ overnight. The bacterial E. coli X-L1-Blue transformed with pcDNA3.1(+)TRAF6 was cultured in LB medium with anti-aminobenzylpenicillin overnight at $37^{\circ} \mathrm{C}$. The pcDNA3.1(+)TRAF6 plasmid was extracted with the Endo-Free Plasmid DNA Midi kit (D6915-04, Omega Bio-Tek, USA) according to the manufacturer's instructions and digestedKpnI and $\mathrm{XhoI}$ at $37^{\circ} \mathrm{C}$ for 3 hours. Finally, the products were separated, extracted, and purified. According to the manufacturer's instructions, the pcDNA3.1(+)TRAF6 was extracted with an endotoxin-free extraction kit. The plasmid transfection of BEECs ( $\left.1 \times 10^{6} \mathrm{cells} / \mathrm{well}\right)$ was carried out in a 6-wells plate according to the Lipofectamine ${ }^{\mathrm{TM}} 3000$ users' instruction (Invitrogen, USA). $5 \mu \mathrm{g}$ of pcDNA3.1(+) TRAF6, $4 \mu \mathrm{g}$ of pcDNA3.1(+)TRAF6 with 50nM bta-miR-24-3p mimic, pcDNA3.1 empty vector, and pcDNA3.1 empty vector with 50nM bta-miR-24-3p mimic were transfected separately into BEECs. RT-qPCR and Western Blot techniques examined transfection efficiency and specific protein analysis. The supernatant was collected to determine the levels of inflammatory cytokines.

\section{RNA Extraction and Quantitative Reverse Transcription-Polymerase Chain Reaction Assay}

Total RNA was isolated from the experimented cells and tissues using TRIzol, according to the manufacturer's instructions (9108, Takara, Shiga, Japan). The RNA quality in all the performed experiments is shown in Supplementary Tables 1-3. Then, cDNA was synthesized using an Emo-M-MLV RT kit (AG11705, Accurate Biotech, Hunan, China). SYBR Green Premix Pro Taq HS kits were used to perform real-time PCR with total cDNA as the starting material. (AG1A1430, Accurate Biotech, Hunan, China) to determine related inflammatory cytokine expression levels (TNF- $\alpha$, IL- $1 \beta$, IL-6, and IL-8) and TRAF6. The expression of miRNAs was confirmed using total RNAs from each sample isolated, and a customized Hairpin-it ${ }^{\mathrm{TM}}$ microRNA qPCR Quantitation Kit (QPM-041, GenePharma, Shanghai, China) was used to analyze bta-miR-24-3p expression values. The $2^{-\Delta \Delta \mathrm{Ct}}$ method is used to analyze expression

Table I Primers Sequence Used for miRNA and Si-RNA

\begin{tabular}{|l|l|}
\hline Oligonucleotide & Sequence (5'-3') \\
\hline bta-miR-24-3p mimics & $\begin{array}{l}\text { Sense-UGGCUCAGUUCAGCAGGAACAGTT- } \\
\text { Antisense-GUUCCUGCUGAACUGAGCCAUUTT }\end{array}$ \\
\hline Mimic Negative control & $\begin{array}{l}\text { Sense -UUCUCCGAACGUGUCACGUTT- } \\
\text { Antisense-ACGUGACACGUUCGGAGAATT- }\end{array}$ \\
\hline Si-TRAF6 & $\begin{array}{l}\text { Sense- UACUGCAUCAAUGUCUACAATT- } \\
\text { Antisense- -UUGUAGACAUUGAUGCAGUATT- }\end{array}$ \\
\hline Si-NC & $\begin{array}{l}\text { Sense -UUCUCCGAACGUGUCACGUTT- } \\
\text { Antisense -ACGUGACACGUUCGGAGAATT- }\end{array}$ \\
\hline
\end{tabular}


Table 2 Primers Used for Quantitative Real-Time PCR (RT-qPCR)

\begin{tabular}{|c|c|c|c|}
\hline Gene & Primer sequence (5'-3') & (bp) & Accession Number \\
\hline Bta-IL-I $\beta$ & $\begin{array}{l}\text { F-ACCAGCTCTACAACAAAAGA- } \\
\text { R-TTGCACTTTACTGACTGCAC- }\end{array}$ & 157 & NM_174093.2 \\
\hline Bta-IL-6 & $\begin{array}{l}\text { F-AGGCAGACTACTTCTGACCA- } \\
\text { R-TACTCCAGAAGACCAGCAGT }\end{array}$ & 160 & NM_I73923.2 \\
\hline Bta-IL-8 & $\begin{array}{l}\text { F-CTGCAGTTCTGTCAAGGATG- } \\
\text { R-CAACCTTCTGCACCCACTTT- }\end{array}$ & 160 & NM_173925.2 \\
\hline Bta-TNF $\alpha$ & $\begin{array}{l}\text { F-CAGTCTCCTACCAGACCAAG- } \\
\text { R-CAGGTTGGGCAGGTTAGAA- }\end{array}$ & 160 & NM_I73966.3 \\
\hline Bta-TRAF6 & $\begin{array}{l}\text { F-GAGACAGGTTTCTTGTGACAAC- } \\
\text { R-TGGCAACCAAAAGTACTGAATG- }\end{array}$ & 160 & NM_I74198.6 \\
\hline Mus-IL-I $\beta$ & $\begin{array}{l}\text { F-CCTGGGCTGTCCTGATGAGAG } \\
\text { R-TCCACGGGAAAGACACAGGTA }\end{array}$ & $|3|$ & NM_00836I.4 \\
\hline Mus-IL-6 & $\begin{array}{l}\text { F-GGCGGATCGGATGTTGTGAT } \\
\text { R-GGACCCCAGACAATCGGTTG }\end{array}$ & 199 & NM_03II68.I \\
\hline Mus-IL-8 & $\begin{array}{l}\text { F-TACTCCAGAAGACCAGCAGT } \\
\text { R-CTGCAGTTCTGTCAAGGATG }\end{array}$ & 199 & NP_000575.I \\
\hline Mus-TNF $\alpha$ & $\begin{array}{l}\text { F-CTTCTCATTCCTGCTTGTG } \\
\text { R-ACTTGGTGGTTTGCTACG }\end{array}$ & 199 & NM_0I3693.3 \\
\hline Mus-TRAF6 & $\begin{array}{l}\text { F-ATGCGGCCATAGGTTCTGC } \\
\text { R-TCCTCAAGATGTCTCAGTTCCAT }\end{array}$ & 199 & NP_033450 \\
\hline Mus-miR-24-3p & $\begin{array}{l}\text { F-TGGCTCAGTTCAGCAGGAACAG } \\
\text { R-GCGGTCATCGACACGCTACGCACG }\end{array}$ & 189 & \\
\hline Mus-U6sn & $\begin{array}{l}\text { F-GCTTCGGCAGCACATATACTAA } \\
\text { R-CGCTTCAGAATTTGCGTGTCAT }\end{array}$ & 196 & \\
\hline Mus- $\beta$-actin & $\begin{array}{l}\text { F-GACATCAAGGAGAAGCTCTG } \\
\text { R-TGGAATTGAAGGTAGTTTCG }\end{array}$ & $24 I$ & NC_00007I.7 \\
\hline Bta- $\beta$-actin & $\begin{array}{l}\text { F-GACATCAAGGAGAAGCTCTG- } \\
\text { R-TGGAATTGAAGGTAGTTTCG }\end{array}$ & 244 & AFI9I490.I \\
\hline
\end{tabular}

levels. ${ }^{44}$ The relative expression levels of mRNAs were normalized to $\beta$-actin, and bta-miR-24-3p normalized to U6 snRNA. All primer sequences for the analysis of expression levels are shown in Table 2.

\section{Enzyme-linked Immunosorbent Assay (ELISA)}

- All the supernatants were harvested after the designated treatment, and the serum from the blood of the inflammatory model was used to detect the levels of inflammatory cytokines (TNF- $\alpha$, IL-1 $\beta$, IL-6, and IL-8) by using an ELISA kit (SEKB-0363-7, SEKM-0001-4, Solarbio, Beijing, China) according to the manufacturer's directions. The absorbance was read at $450 \mathrm{~nm}$ with an automatic standard microplate reader (BioTek's Epoch ${ }^{\mathrm{TM}}$, USA), and all absorbance results were normalized via standard curves.

\section{Western Blot Analysis}

After the designated experiments, cells and tissues of each group were lysed and centrifuged, total protein was extracted with radioimmunoprecipitation assay reagent (R0010, Bio Sharp, China), and the protein concentrations were measured 
by the BCA method(T9300A, Takara, Inc., Shanghai, China). The protein samples were taken and spotted at $30 \mu \mathrm{g}$ per well, using 10\% sodium dodecyl sulfate-polyacrylamide gel (PG01010, Solarbio, Shanghai, China) electrophoresis for 90 min. The protein was transferred onto the polyvinylidene fluoride (PVDF) membrane by the wet method for 60 minutes. The PVDF membrane was blocked with 5\% bovine serum albumin in Tris-buffered saline with Tween-20 for 60 min at room temperature. Each band of interest was sliced according to the relative molecular mass. The diluted antibody (1:1000) was separately added and incubated overnight at $4{ }^{\circ} \mathrm{C}$, and after washing, was incubated in a diluted secondary antibody (1:3000) tube at room temperature for 60 minutes. After ECL coloration washing, imaging was performed using a chemiluminescence imaging system.

\section{Cellular Immunofluorescence Assay}

- The BEECs transfected and treated were used to perform immunofluorescence staining. Briefly, cells were fixed with 4\% paraformaldehyde for 20 minutes; then, they were immersed with PBS in 1\% Triton X-100 (T8200, Solarbio, Beijing, China) to permeabilize the cells at room temperature for 25 minutes. The PBS washing was repeated thrice, cleaning and blotting with filter paper and blocking for 30minutes with $10 \%$ goat serum at room temperature. Each cell well in plates with a specific primary antibody $(1: 200)$ was incubated overnight at $4^{\circ} \mathrm{C}$ and then incubated with FITClabeled secondary antibodies $(1: 300)$ in the dark box for 1 hour at $37^{\circ} \mathrm{C}$. Finally, the nuclei were stained using DAPI (ab228549, Abcam, China) for 10 min, washed with PBS, sealed with an anti-fluorescence quencher, and captured fluorescent images with an inverted fluorescence microscope (IX81, Olympus, Japan). The IOD and area of cells were measured by Image-Pro Plus software, and the fluorescence intensity was expressed as IOD/area.

\section{Dual-luciferase Reporter Assay}

According to the prediction result of TargetScan and miRDBSoftwares, TRAF6 was detected to be one of the targets of bta-miR-24-3p. Dual-luciferase reporter experiments were performed in HEK293T cells. Cells were transfected with wild-type fragments of TRAF6 (TRAF6- WT) or mutant fragments of TRAF6 (TRAF6-MUT of the TRAF6 gene 3'-UTR cloned into pmiRGLOluciferase reporter vector, and then transfected into bta-miR-24-3p mimics or mimics NC with a final concentration as required. After 24 hours of transfection at $37^{\circ} \mathrm{C}$, cells were lysed and analyzed for luciferase activities with a luciferase detection kit (A1276, GenePharma, Shanghai, China). The Renilla luciferase/ luciferase ratio (Rluc/Luc) was recorded.

\section{Statistical Analysis}

All data were analyzed and shown as mean \pm SD based on at least three experiments. Data from different groups were tested for normality and homogeneity of variance. Multiple comparison analysis was performed on the significant factors to determine the optimal value. The differences between groups were compared by Student's $t$-test or one-way analysis of variance (ANOVA). GraphPad Prism 8.4 (GraphPad Software, USA) was applied for statistical analysis and plotting. A p-value $<0.05$ or $<0.01$ was considered statistically significant.

\section{Results}

\section{Altered miR-24-3p Expression in Uterus After LPS Induced Injured Endometrium in Mice}

An LPS-induced endometritis mouse model was established to determine whether miR-24-3p had been changed in Endometritis. Edema and hemorrhages were found in the endometritis mouse model compared with the control group showing a typical endometrial structure (Figure 1A). The wet to dry weight of the uterus in the experimental group weighed higher than the control (Figure 1B). H\&E staining of the uterine tissues from the endometritis group displayed apparent pathological changes, including many epithelial hemorrhages and inflammatory cell infiltration (Figure 1C). The inflammatory response degree in the endometrium was evaluated by subsequent RT-qPCR assay. We then determined the miR-24-3p expression in the uterine tissues, and the expression of miR-24-3p was dramatically repressed $(p<0.01)$ in the LPS group compared to the endometritis group (Figure 1D). The expression levels of TRAF6 mRNA and related pro-inflammatory 
A

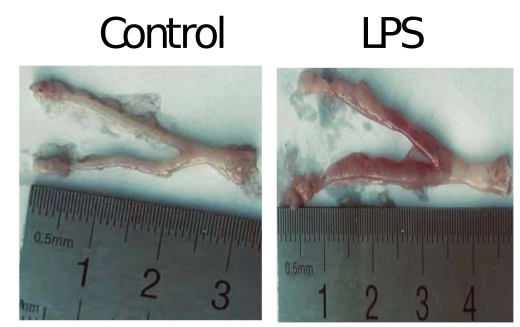

C

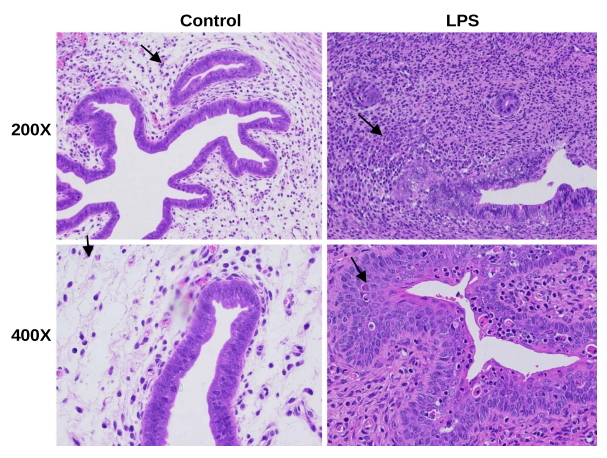

E

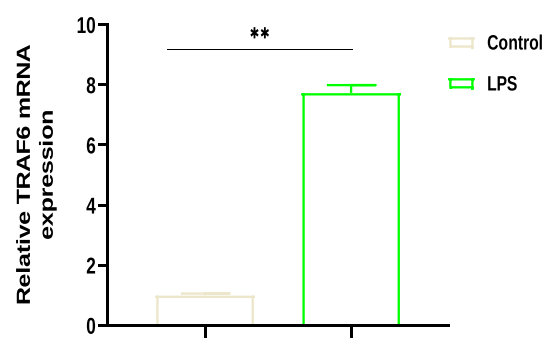

G

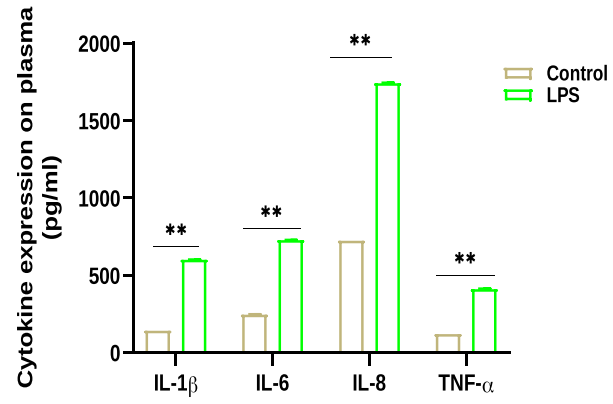

B

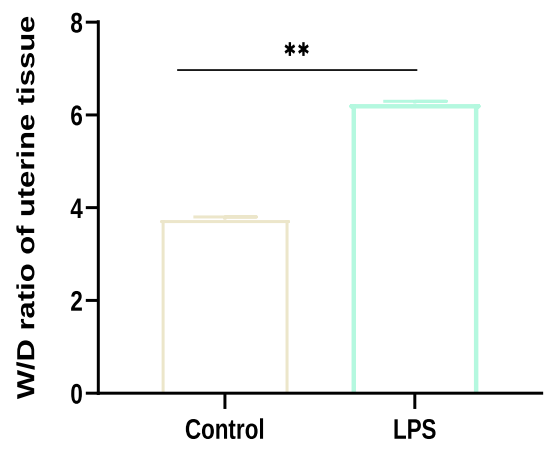

D

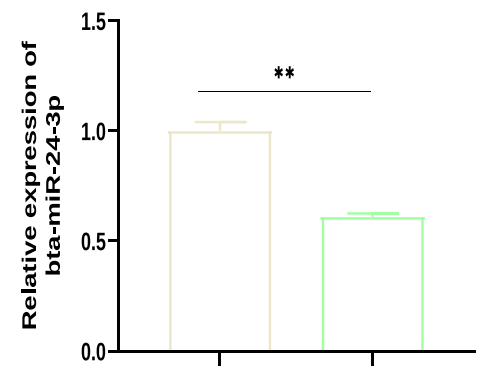

F

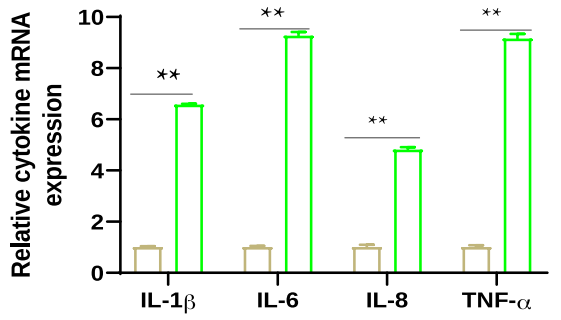

Figure I The expression of miR-24-3p, TRAF6, and pro-inflammatory cytokines in uterine tissue of LPS-induced endometritis mice. (A) After 24 hr of LPS perfusion of the mouse uterus, the degree of gross inflammation in the uterine sample was assessed by visualization and metric. (B) W/D ratio of uterine tissue ( $n=3)$. $(\mathbf{C}) \mathrm{H} \& \mathrm{E}$ staining of uterine tissue (black arrows), scale bar: $100 \mu \mathrm{m}$, magnification: $200 \mu \mathrm{m}$ and $400 \mu \mathrm{m}(\mathrm{n}=3)$. (D) TRAF6 expression in uterine tissue of LPS-treated mice by qRT-PCR ( $\mathrm{n}=6$ ) $\beta$-actin was used as an internal control. (E) miR-24-3p expression in uterine tissue of LPS-treated mice by qRT-PCR $(n=6)$. U6 snRNA was used as an internal control. (F) Pro-inflammatory cytokine IL-I $\beta$, IL-6, IL-8, and TNF- $\alpha$ mRNA levels were determined by qRT-PCR. (G) The levels of the pro-inflammatory cytokines IL-I $\beta$, IL-6, IL-8, and TNF- $\alpha$, were determined by ELISA $(n=3)$. Data was present as mean \pm SD of three independent experiments. ** $p<0.01$ (Student's $t$-test).

Abbreviations: ELISA, enzyme-linked immunosorbent assay; H\&E, hematoxylin/eosin; LPS, lipopolysaccharide; mRNA, messenger RNA; qRT-PCR, Real-Time quantitative polymerase chain reaction; IL-I $\beta$, interleukin-I $\beta$; TNF- $\alpha$, tumor necrosis factor- $\alpha$; W/D, wet weight to dry weight. 
A

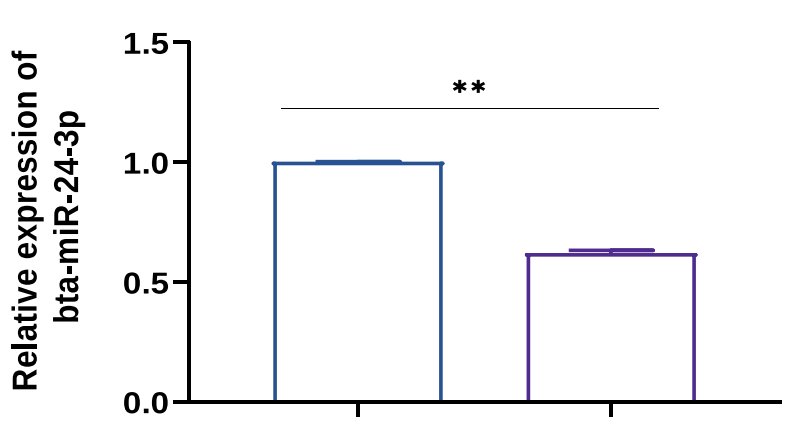

C

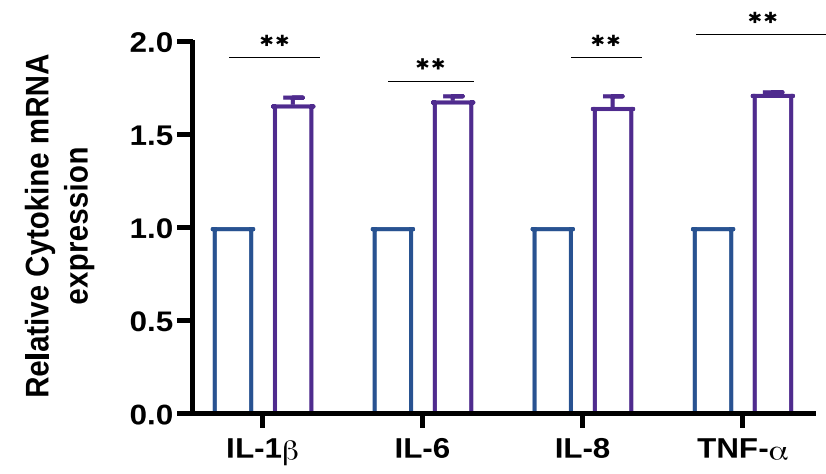

B

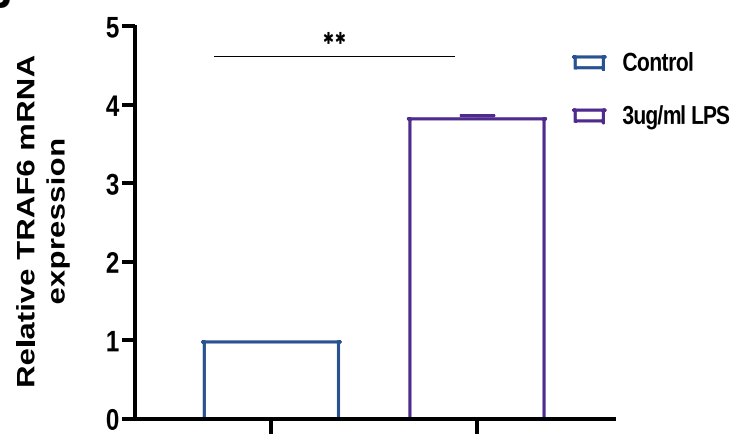

D

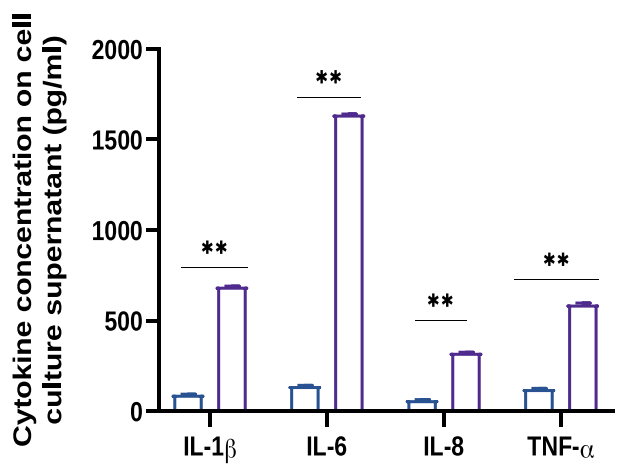

Figure 2 Relative expression of miR-24-3p, TRAF6, and pro-inflammatory cytokines in LPS-triggered BEECs. (A) RT-qPCR was used to detect bta-miR-24-3p expression in LPS-induced inflammation in BEECs. U6 snRNA was used as an internal control. (B) TRAF6 expression in LPS-induced inflammation in BEECs was detected by RT-qPCR $\beta$ actin was used as an internal control. (C) The pro-inflammatory cytokines IL-I $\beta$, IL-6, IL-8, and TNF- $\alpha$, were detected by RT-qPCR (D). The pro-inflammatory cytokines (ILI $\beta$, IL-6, IL-8, and TNF- $\alpha$ ) from cell supernatant were detected by ELISA. Data represent three independent experiments and are presented as the mean \pm SEM. Student's t-test, ${ }^{* *} \mathrm{p}<0.01$.

cytokines (IL-1 $\beta$, IL-6, IL-8, and TNF- $\alpha$ ) were also detected. These results revealed that TRAF6 (Figure 1E) and the proinflammatory cytokines were significantly upregulated in the LPS-stimulated group compared with the control group(p $<$ 0.01) (Figure $1 \mathrm{~F}$ and $\mathrm{G}$ ). This result demonstrated that the mouse endometritis model was successful. The inflammatory model revealed that aberrant miR-24-3p expression is closely correlated with the pathogenesis of Endometritis.

\section{Changes in miR-24-3p, TRAF6, and Pro-Inflammatory Cytokines in BEECs Following Triggered by LPS}

The role of miR-24-3p in LPS-induced endometrial inflammation was further investigated by the expression level of miR-24-3p in LPS- stimulated BEECs. In order to uncover the role, primary bovine endometrial epithelial cells (BEECs) and stimulated with LPS for 24 hours. The degree of inflammatory induction in the BEECs was further evaluated by subsequent RT-qPCR assay. As displayed in Figure 2A, miR-24-3p expression was remarkably down-regulated upon LPS stimulation. The expression level of TRAF6 was remarkably upon LPS induction in BEECs (Figure 2B). The proinflammatory cytokines IL-1 $\beta$, IL-6, IL-8, and TNF- $\alpha$, were noticeably upregulated (Figure $2 \mathrm{C}$ and D). Therefore, these results implied that miR-24-3p is involved in the LPS-triggered innate immune response.

\section{Inhibiting of the Expression of Pro-inflammatory Cytokines and TRAF6 by miR-24-3p in BEECs}

To further portray the specific molecular function of miR-24-3p in LPS-mediated inflammatory processes, miR-24-3p mimics were transiently transfected into BEECs.CCK-8 assay was used to examine whether cell viability is affected by 
the administration of miR-24-3p mimics with LPS induction, thus identifying the optimal time for stimulation. The results showed that cell viability is not affected by miR-24-3p mimics with LPS induction ( $3 \mu \mathrm{g} / \mathrm{mL})$, indicating that miR-24-3p mimics with LPS stimulation have no significant effect on cell growth and proliferation (Figure 3A). The expression of miR24-3p was significantly increased by RT-qPCR assay on transfection with miR-24-3p mimics or negative control for 24 hours (Figure 3B). After 24 hours of stimulation of cells with LPS $(3 \mu \mathrm{g} / \mathrm{mL})$, the expression levels of TRAF6 were remarkably upon LPS induction in BEECs determined by RT-qPCR (Figure 3C). ELISA and RT-qPCR determined the expressions of inflammatory cytokines. As shown in Figure 3D and E, LPS-mediated productions of pro-inflammatory cytokines were remarkable negatively correlated with the expression of miR-24-3p. These results demonstrated that miR-24-3p regulates the inflammatory process as an anti-inflammatory factor in LPS-triggered inflammation.

\section{TRAF6 as a Target of miR-24-3p in the NF-KB/MAPK Signaling Pathways}

TargetScan computational bioinformatical algorithms were used to identify the putative target of miR-24-3p for 3'-UTR of TRAF6 mRNA, which contributes to the effect of the NF-KB/MAPK signaling pathways. The putative binding sites for TRAF6 3'-UTR and miR-24-3pare indicated in Figure 4A. Further studies demonstrated that a dual-luciferase expression system verified miR-24-3p directly targeted TRAF6 mRNA. The results showed that the miR-24-3pmimics significantly inhibited the luciferase activity wild-type 3'-UTR of TRAF6, whereas the mutant 3'-UTR of TRAF6 did not change (Figure 4B). The above results demonstrated that inhibition of TRAF6 expression could be regulated by miR-24-3p directly targeting the 3'-UTR of TRAF6 mRNA. The expression levels of TRAF6 were remarkably decreased upon miR24-3pmimics in BEECs determined by RT-qPCR (Figure 4C). It is widely acknowledged that various signaling pathways can regulate inflammatory cytokines and that the NF- $\mathrm{KB}$ / MAPK signaling pathway is the most important one. NF- $\mathrm{kB} /$ MAPK plays an important role in LPS-induced Endometritis. To further understand the mechanism that miR-24-3p suppressed inflammatory cytokines, we investigated the effect of miR-24-3p on the NF- $\mathrm{KB}$ / MAPK signaling pathway.

The protein levels of TRAF6, p-IKB $\alpha$, and p-p65 that LPS upregulated were observably inhibited after miR-24-3p overexpression even with LPS- stimulation, as detected by Western blot analysis (Figure 4D and E). These results demonstrate that miR-24-3p impairs LPS-triggered inflammatory response by restraining the activation of the NF- $\mathrm{kB}$ pathway. Likewise, p-p38, p-ERK, and p-JNK's protein levels were also increased upon LPS-induction but inhibited by miR-24-3p overexpression (Figure 4F and G). Moreover, immunofluorescence experiments were performed and demonstrated that miR-24-3pmimics had similar results after $24 \mathrm{hr}$ of LPS intervention (Figure $4 \mathrm{H}$ and I). These data revealed that miR-24-3p suppressed TRAF6 expression and further inhibited LPS-induced activation of the NF- $\mathrm{kB} /$ MAPK signaling pathways.

\section{Knockdown of the TRAF6 Gene in BEECs Attenuated Pro-Inflammatory Cytokines and Gene Expression Through NF-KB/MAPK Signaling Pathways}

In order to examine the regulatory mechanism potential of TRAF6 on LPS-mediated inflammatory responses, there is a need for transfection of Si-TRAF6 to be knocked down by TRAF6 expression in BEECs compared with si-NC with LPS-stimulation. The mRNA expression level of TRAF6 was down-regulated by RT-qPCR experiments due to the knockdown of TRAF6, as shown in Figure 5A and B. The expression levels of the pro-inflammatory cytokines (IL-1 $\beta$, IL-6, IL-8, and TNF- $\alpha$ ) were also inhibited following knockdown of TRAF6 (Figure 5C), which is consistent with the anti-inflammatory potential of bta-miR-24-3p mimic. Furthermore, there was a reduction in the concentration of proinflammatory cytokines upon silencing TRAF6 in BEECs, as shown in Figure 5D. Furthermore, our study revealed that knockdown of TRAF6 significantly inhibited the protein expression of TRAF6, p65 and IKB $\alpha$, similar to those of the above results in the bta-miR-24-3p overexpression experiment (Figure 5E and F) and significant inhibition of the protein level of p-p38, p-ERK, and p-JNK were also increased upon LPS-induction with silencing of TRAF6 (Figure 5G and $\mathrm{H}$ ). In addition, Immunofluorescence staining also showed a similar phenomenon (Figure 5I and J). Therefore, our findings clearly showed that the LPS-induced inflammatory response was associated with the negative regulation of the NF- $\mathrm{kB}$ / MAPK pathway by bta-miR-24-3p targeting TRAF6. 
A

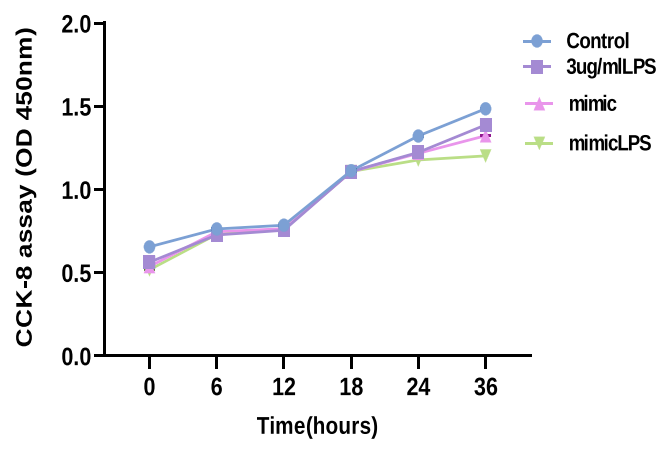

C

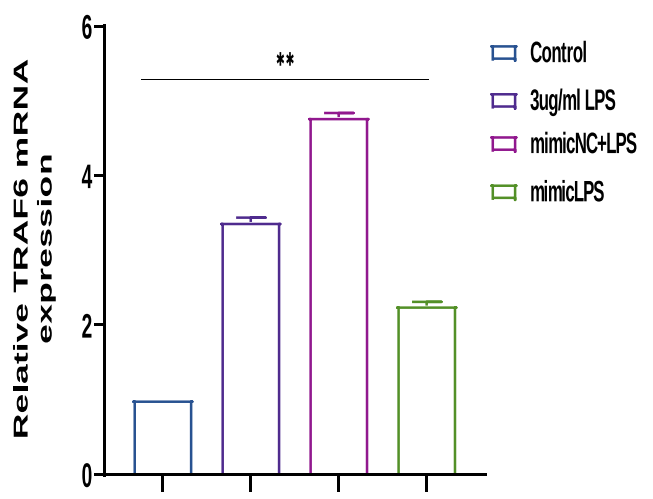

B

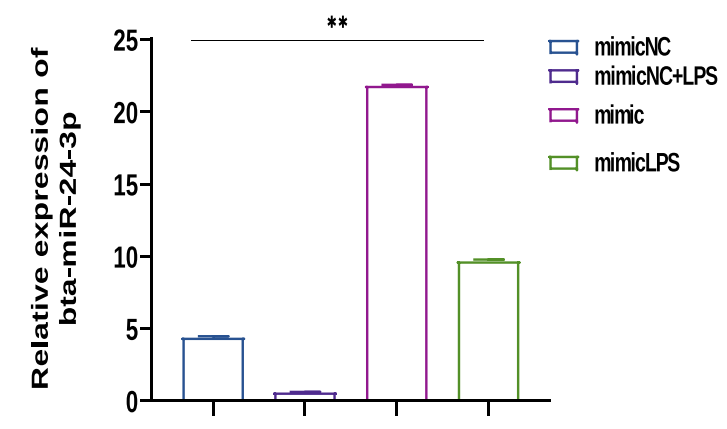

D

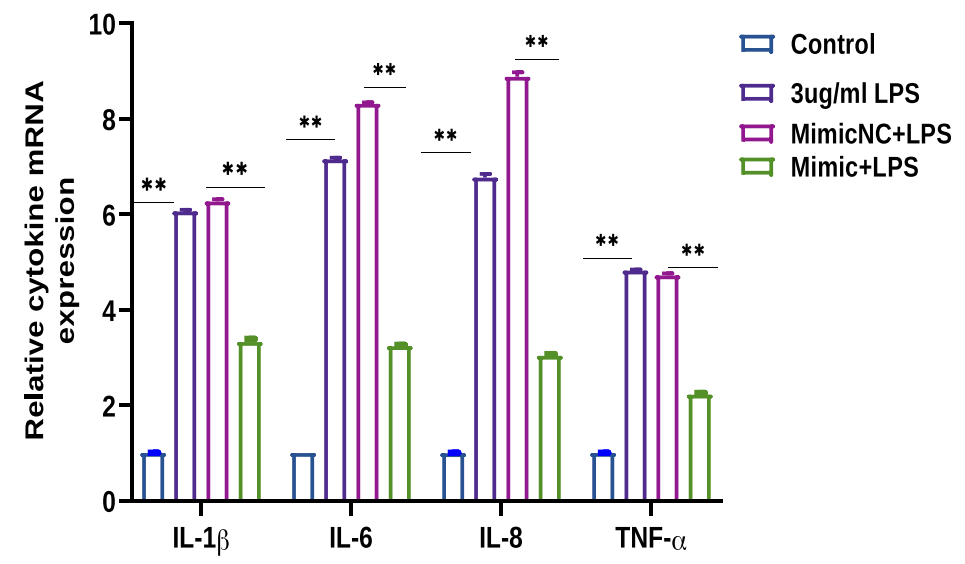

E

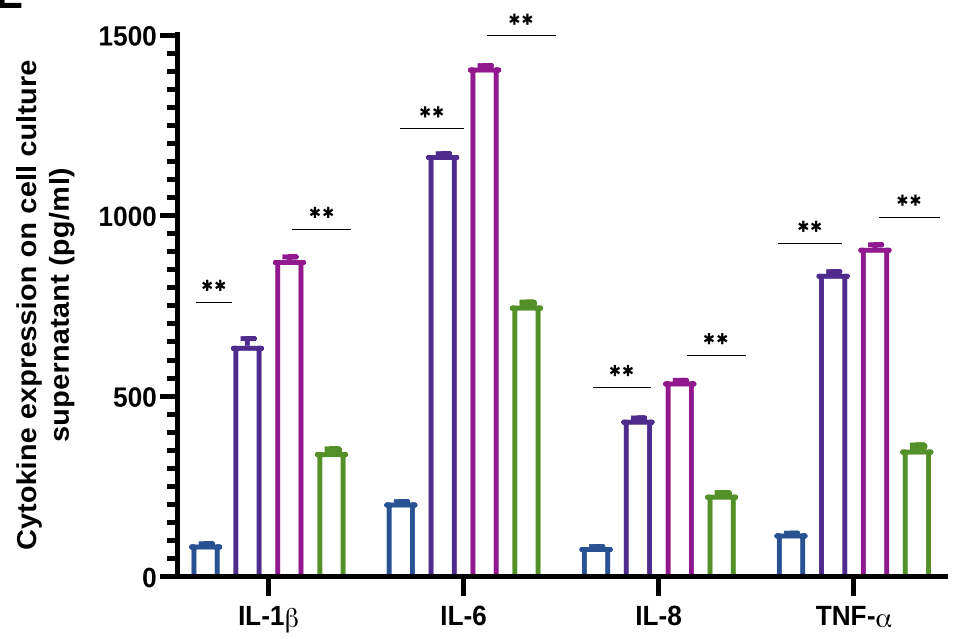

Figure 3 Bta-miR-24-3p mimics modulate overexpression of pro-inflammatory cytokines and TRAF6 in BEECs. Cells were transfected with bta-miR-24-3p mimics or btamiR-24-3pNC for 7hours, and ordinary BEECs served as the control group. Then each treatment group was stimulated with $3 \mu \mathrm{g} / \mathrm{mL}$ LPS for $24 \mathrm{hours}$. (A) CCK-8 assays of BEECs after transfection with bta-miR-24-3p mimics. (B) RT-qPCR was used to detect bta-miR-24-3p expression in the transfection experiment, U6 snRNA was used as an internal control. (C) TRAF6 expression detected by RT-qPCR, $\beta$-actin was used as an internal control. (D) RT-qPCR determined the expression of cytokines IL-I $\beta$, IL-6, IL-8, and TNF- $\alpha$. $\beta$-actin was used as an endogenous control. (E) The cell supernatant from the transfection experiment was harvested to evaluate the cytokine concentration using the ELISA method. The data were presented with triplicate experimental observations as mean \pm SD. ${ }^{* *} \mathrm{p}<0.0 \mathrm{I}$. (Student's $t$-test). 


\section{A}

Position 171-178 of TRAF6 $3^{\prime}$ UTR

TRAF6-WT- 3' UTR5'........CUGUCCCUUUUCCCAGUGUCCUU......3'

Bta-miR-24-3p 3'-UGGCUCAGUUCAGCAGGAACAGU-5'

TRAF6-MUT-3'UTR 5'.....UACUGCAUCAAUGUCAUGUUCAA.....3'
B

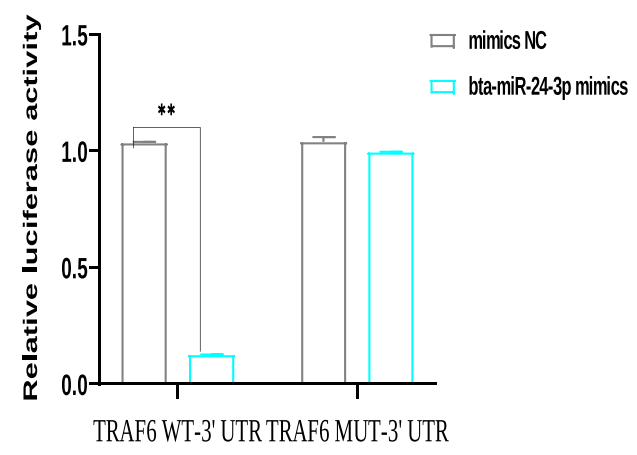

C

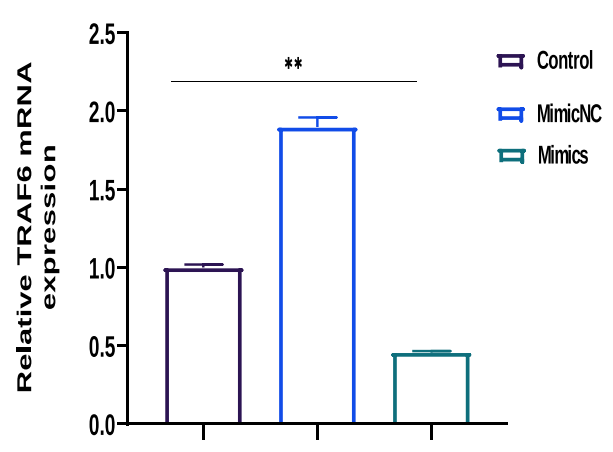

E

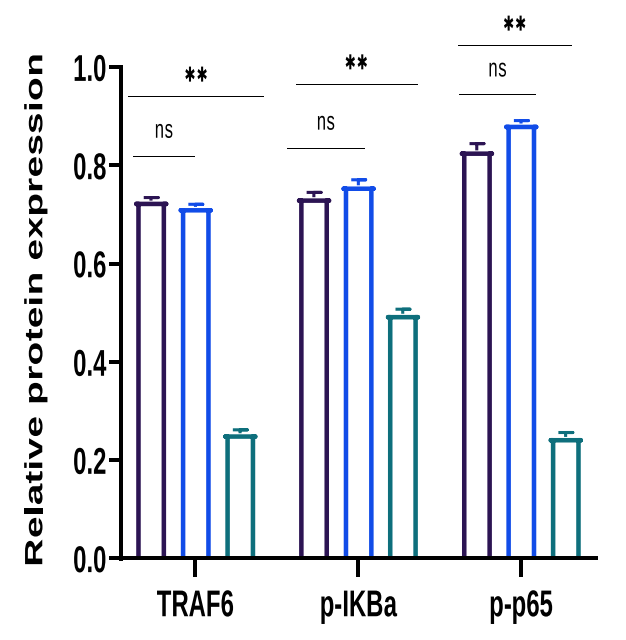

D

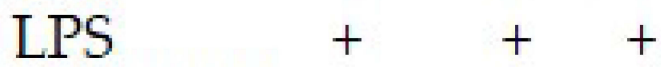

MimicNC - + -

Mimic

$+$

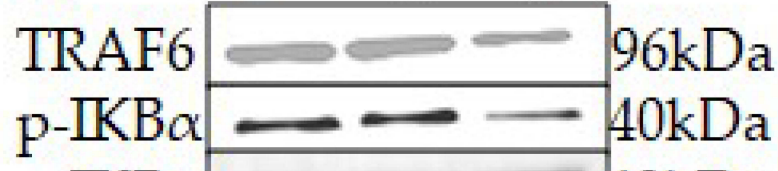

IKB $\alpha=40 \mathrm{kDa}$

$\mathrm{p}-\mathrm{p} 65=65 \mathrm{kDa}$

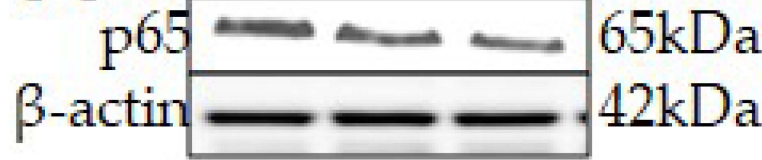

$\mathbf{F}$

口 LPS

ㅁ. MimicNC+LPS

口 MimictLPS

LPS

MimicNC - + -

Mimic

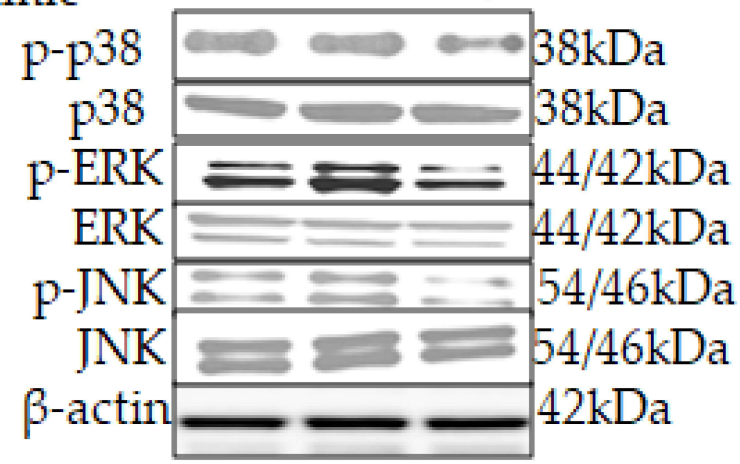

Figure 4 Continue. 

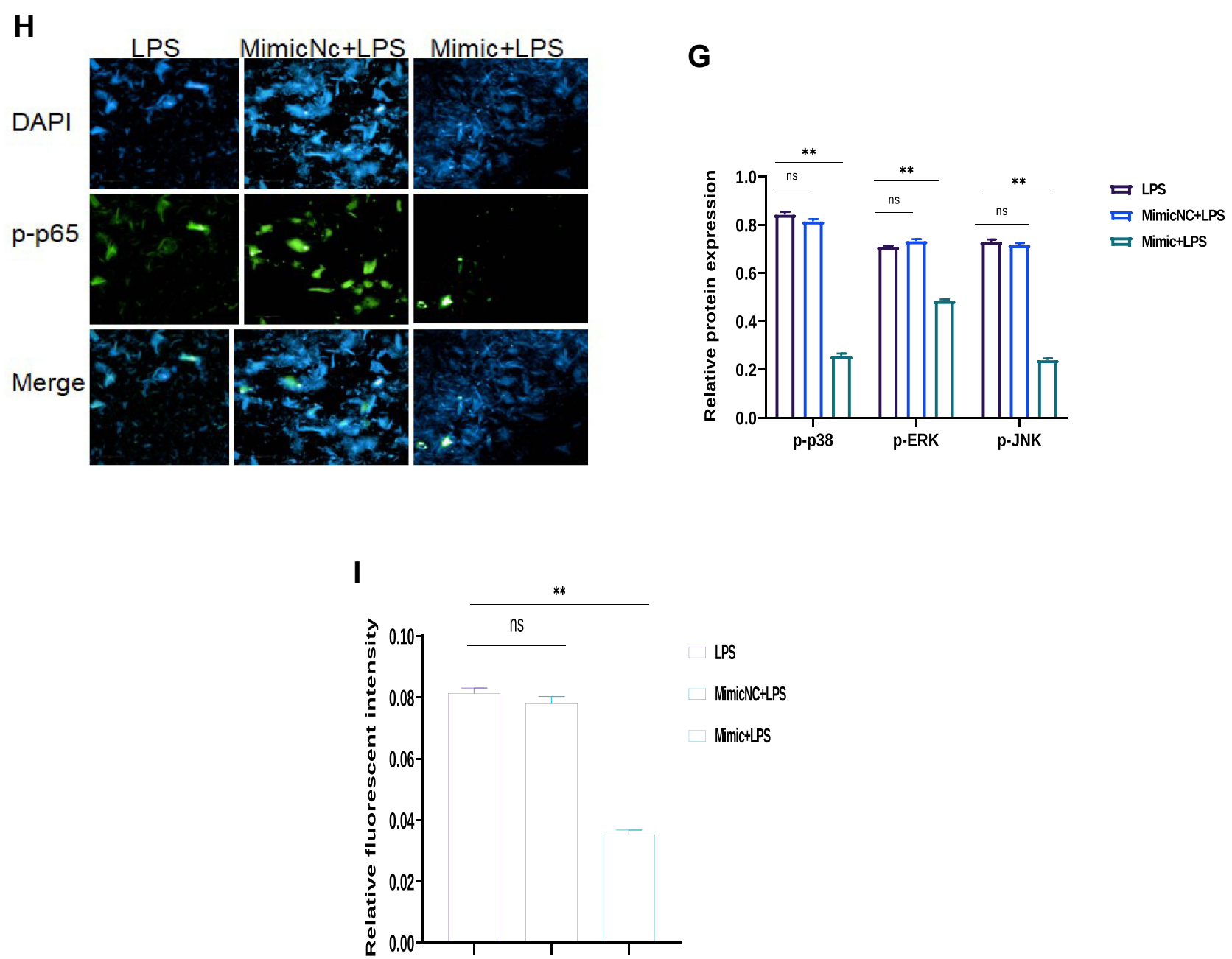

Figure 4 Identification of Tumor necrosis factor receptor-associated factor 6 (TRAF6) as a target gene of bta-miR-24-3p (A) According to the TargetScan, the bta-miR-24$3 p$ target site in the sequence of TRAF6 was predicted. (B) The luciferase reporter gene assay measured the fluorescence activity of the TRAF6 3 'UTR in HEK293T cells that were co-transfected with wild-type TRAF6 3'UTR and bta-miR-24-3p, or mutational type TRAF6 3'UTR and bta-miR-24-3p, respectively (C) qRT-PCR was used to determine the mRNA expression level of TRAF6 in BEECs transfected with miR-24-3p mimics, or scramble, respectively; $\beta$-actin was used as an endogenous control. (D) Cells were transfected with bta-miR-24-3p mimics or bta-miR-24-3pNC for 7hours. Ordinary BEECs served as the control group was all later treated with $3 \mu$ g/mL for 24hours, proteins were later extracted, The expression of TRAF6, $\mathrm{p}-\mathrm{lK} \mathrm{K} \alpha, \mathrm{p}-\mathrm{p} 65$ proteins was detected in transfected and treated $\mathrm{BEEC}$ s by Western blot technique (E). The gray values of TRAF6, p-plKB $\alpha$, p-p65 in different treatment groups were measured by IPP6.0 software. (F) The protein extraction followed the same way as in (E). The Western blot technique detected the expression of p-p38, p-ERK, and p-JNK proteins in transfected and treated BEECs (G). The gray values of p-p38, p-ERK, p-JNK proteins in different treatment groups were measured by IPP6.0 software. $(\mathbf{H})$ The $\mathbf{6 5}$ translocation was detected by immunofluorescence staining $(\times 400$, scale bar $=$ $100 \mu \mathrm{m}$ ). The nucleus emits blue fluorescence, and the green spots indicate p-p65 fluorescence staining. (I) The IOD/area was measured by IPP 6.0 software to represent the relative fluorescence intensity of $\mathrm{P}-\mathrm{p} 65$, with DAPI's IOD as an internal control. Data are represented by the mean \pm SD of three independent experiments. $* * P<0.01$. (Student's $t$-test).

Abbreviation: Ns, not significant.

\section{MiR-24-3p Regulates the Inflammatory Response by Targeting TRAF6}

The recombinant DNA cloning vector of TRAF6 was transfection into BEECs. The CCK-8 cell viability assay result showed no significant difference among the pcDNA3.1 empty vector, pcDNA3.1+ bta-miR-24-3pmimics, pcDNA3.1TRAF6, and pcDNA3.1- TRAF6 and bta-miR-24-3pmimics ( $>$ 0.01) (Figure 6A). TRAF6 overexpression vector (pcdna3.1-TRAF6) was successfully generated to validate the regulating effect of TRAF6 on BEECs. TRAF6 mRNA expression levels increased significantly after transfecting BEECs with pcDNA3.1-TRAF6 (Figure 6B). However, the bta-miR-24-3p mimic decreased TRAF6 expression, indicating that pcDNA3.1-TRAF6 might be employed in future investigations. The overexpression of bta-miR24-3p decreased TRAF6 expression at mRNA levels; however, it could not be reversed after the co-transfection of bta-miR24-3p mimicsTRAF6 overexpression vector was introduced (Figure 6C). 
A

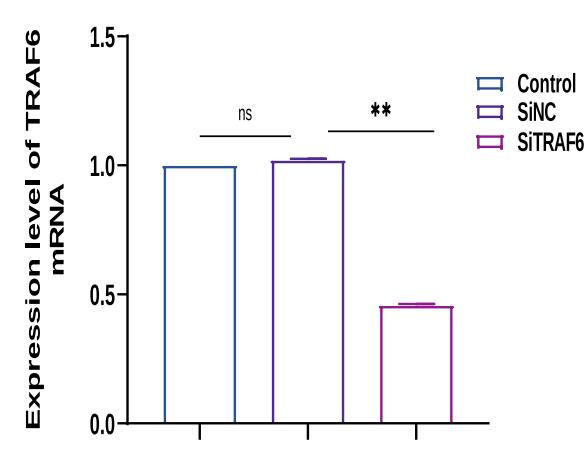

C

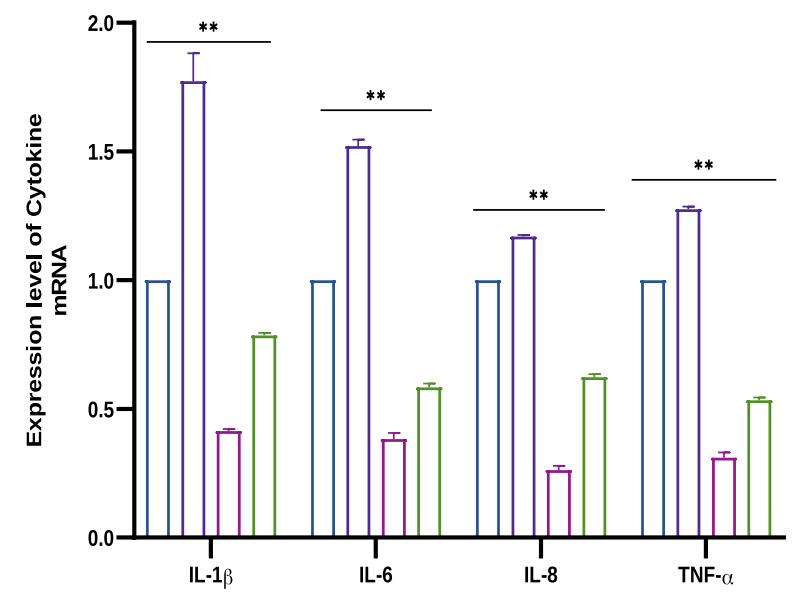

E

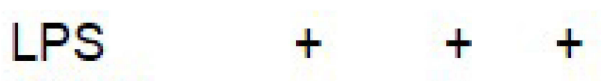

Si-NC $\quad-\quad+\quad-$

Si-TRAF6 - - +

TRAF6 $=96 \mathrm{kDa}$

$\mathrm{p}-\mathrm{IKBa}=40 \mathrm{kDa}$

$\mathrm{IKBa} \longrightarrow 40 \mathrm{kDa}$

$\mathrm{p}-\mathrm{p} 65=-65 \mathrm{kDa}$

p65 $=65 \mathrm{kDa}$

$\beta$-actin
B

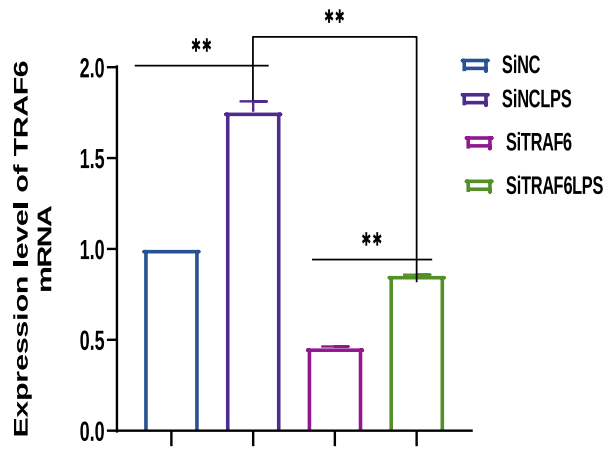

D

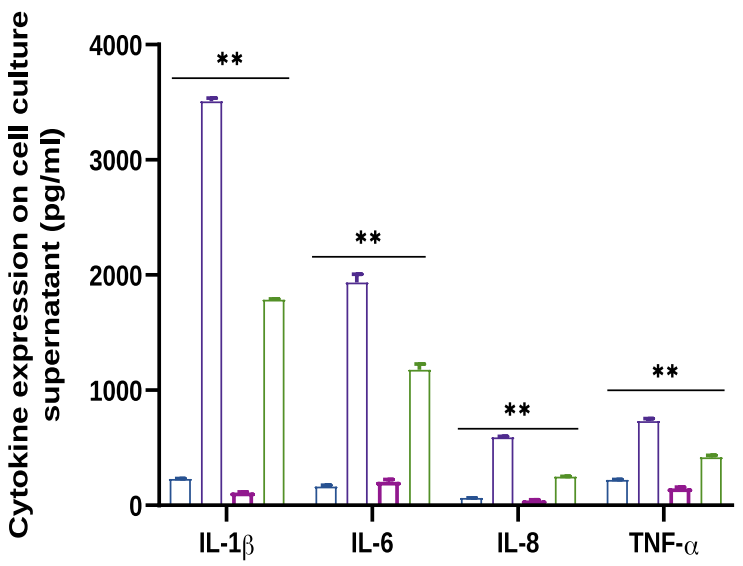

Figure 5 Continue.

$\mathbf{F}$

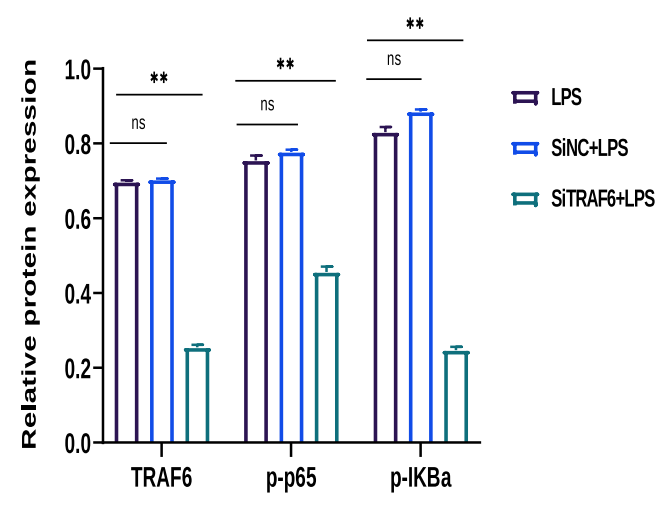


G

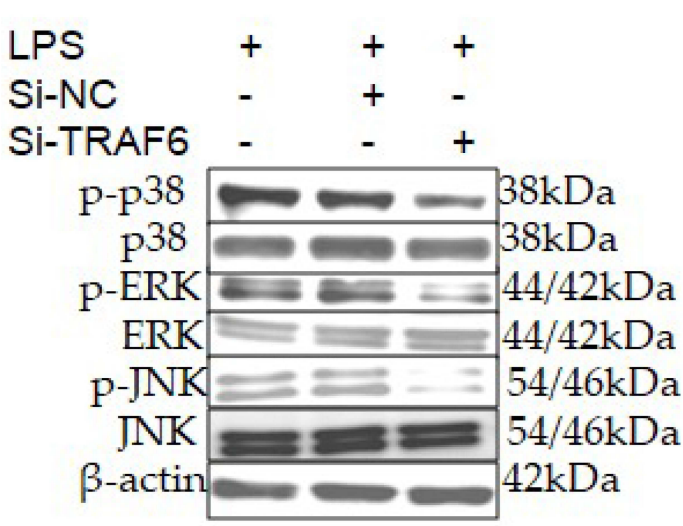

H

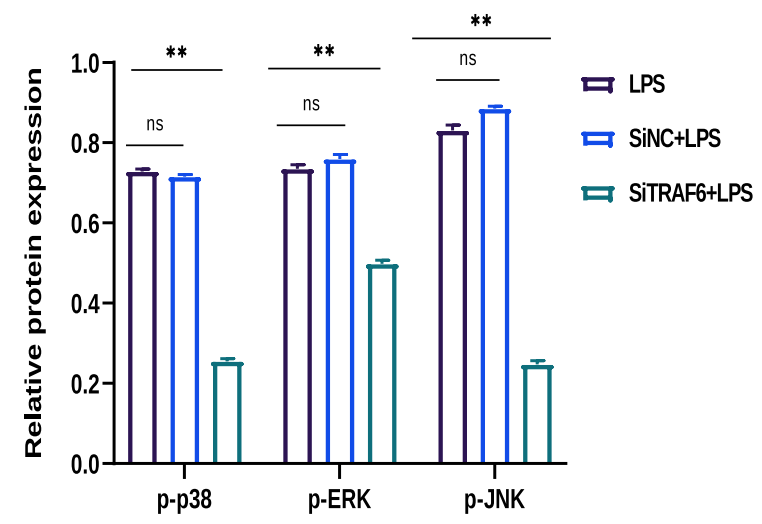

I
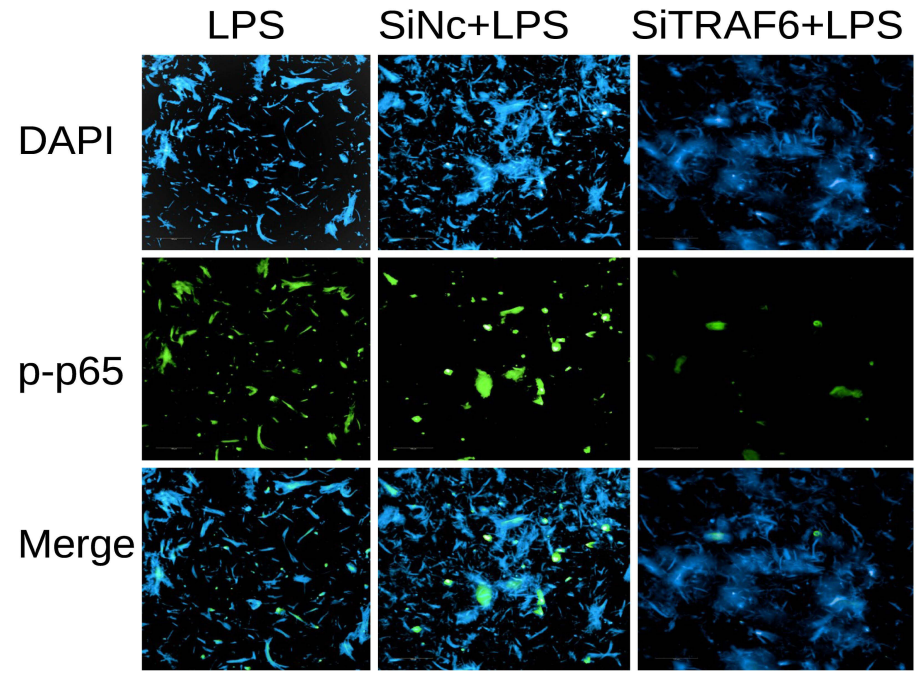

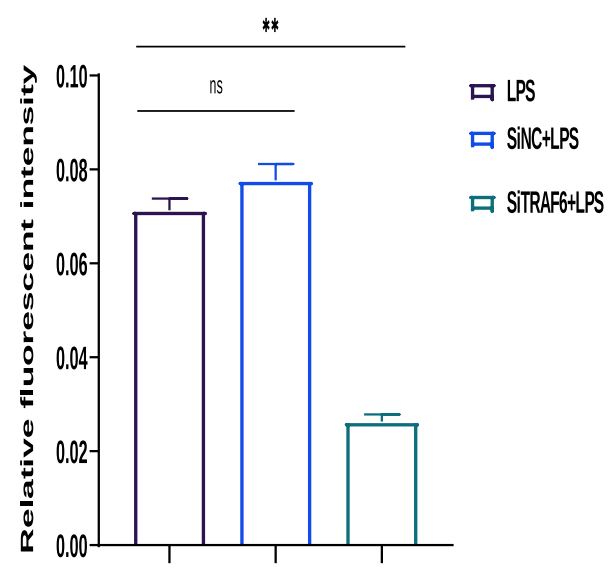

Figure 5 Knockdown of the TRAF6 gene in BEECs attenuated pro-inflammatory cytokines and gene expression through NF-KB/MAPK signaling pathways. (A)The Si-TRAF6 or Si-NC have been transfected into BEECs for 7 hours transfection, qRT-PCR was used to determine the mRNA expression level of TRAF6 in BEECs transfected with the Si-TRAF6 or Si-NC, respectively; $\beta$-actin was used as an endogenous control. (B) The Si-TRAF6 and Si-NC have been transfected into BEECs for 7 hours transfection, after which the stimulation with LPS $(3 \mu \mathrm{g} / \mathrm{mL})$ for 24 hours in some specific wells, qRT-PCR was used to determine the mRNA expression level of TRAF6. (C) The Si-TRAF6 and Si-NC have been transfected into BEECs for 7 hours transfection. The stimulation with LPS ( $3 \mu \mathrm{g} / \mathrm{mL})$ for 24 hours in some specific wells shows the expression levels of proinflammatory mediators (IL-I $\beta$, IL-6, IL-8, and TNF- $\alpha$ ) were analyzed with the qRT-PCR technique. (D) The supernatant from the transfection experiment was harvested, and the ELISA technique assayed the pro-inflammatory cytokine concentration of IL-I $\beta$, IL-6, IL-8, and TNF- $\alpha$ in the cell supernatant, respectively. (E) Cells were transfected with Si-TRAF6 or Si-NC for 7hours, and ordinary BEECs served as the control group was all later treated with $3 \mu \mathrm{g} / \mathrm{mL}$ for 24 hours, proteins were later extracted. The Western blot technique detected the expression of TRAF6, p-IKB $\alpha$, p-p65 proteins in transfected and treated BEECs (F). The gray values of TRAF6, p-plkB $\alpha$, p-p65 in different treatment groups were measured by IPP6.0 software. (G) The protein extraction following experiment protocol in (E), The expression of p-p38, p-ERK, p-JNK proteins was detected in transfected and treated BEECs by Western blot technique $(\mathbf{H})$. The gray values of $\mathrm{p}-\mathrm{p} 38, \mathrm{p}$-ERK, $\mathrm{p}-\mathrm{JNK}$ proteins in different treatment groups were measured by IPP6.0 software. (I) Immunofluorescence staining detected the p65 translocation $(\times 400$, scale bar $=100 \mu \mathrm{m})$. The nucleus emits blue fluorescence, and the green spots indicate p-p65 fluorescence staining. (J) The IOD/area was measured by IPP 6.0 software to represent the relative fluorescence intensity of p-p65, with DAPl's $I O D$ as an internal control. Data are represented by the mean \pm SD of three independent experiments. ${ }^{*} \mathrm{p}<0.01$. (Student's $t$-test).

Abbreviation: Ns, not significant.

Furthermore, in co-transfected BEECs, the restoration of TRAF6 could not counteract the anti-inflammatory effects of bta-miR 24-3p on reducing the secretion of inflammatory cytokines (TNF $\alpha$, IL1 $\beta$, IL-8, and IL-6) ( $p>0.01$ ) (Figure 6D and E). Our findings revealed that bta-miR 24-3p might attenuate endometritis progression by inhibiting TRAF6 mRNA expression. The research results have demonstrated the anti-inflammatory potential of bta-miR $24-3 p$ in regulating the LPS-induced bovine Endometritis through attenuation of the NF- $\mathrm{BB}$ / MAPK cellular signaling pathway by targeting TRAF6 (Figure 7). 
A

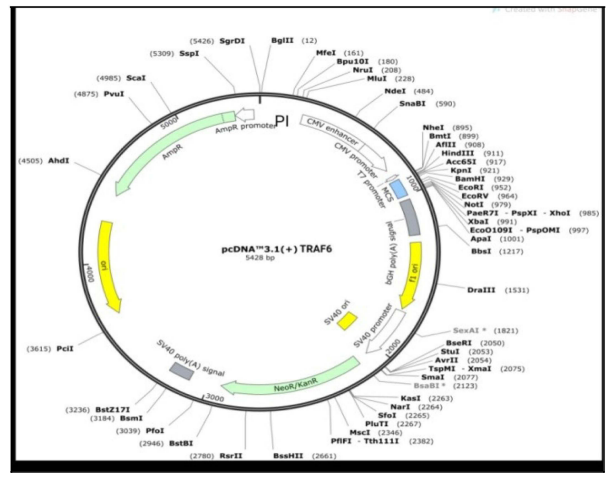

B

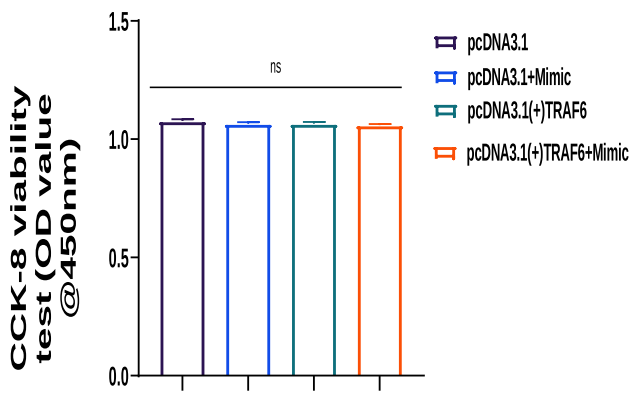

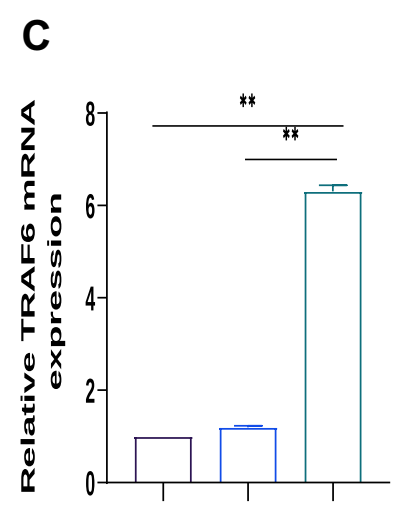
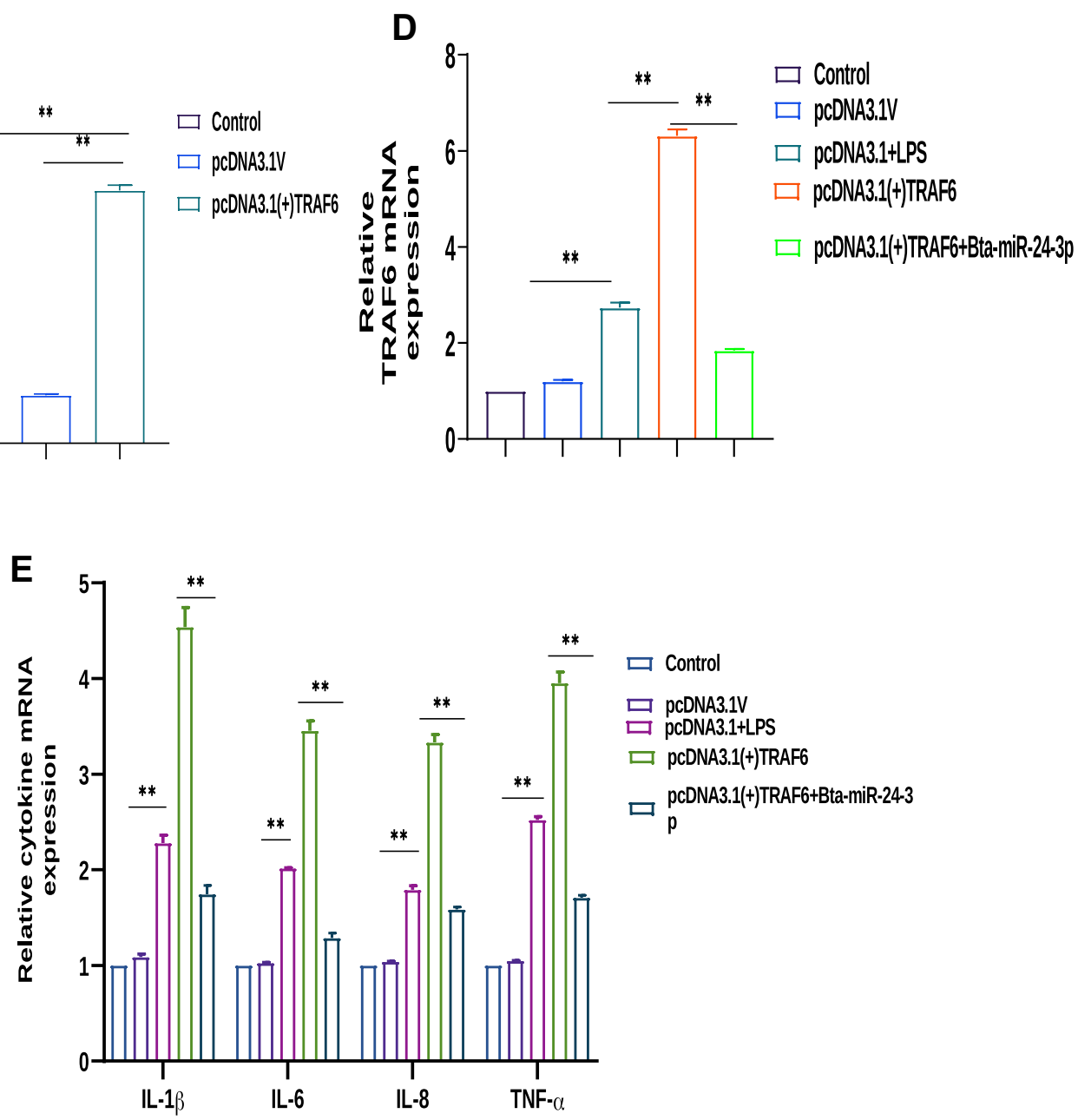

Figure 6 Bta-miR-24-3p attenuated TRAF6 expression in BEECs co-transfected with cloned TRAF6. (A and B) The pcDNA3.I empty vector, pcDNA3.I empty vector and bta-miR-24-3pmimics, pcDNA3.I(+)TRAF6, pcDNA3.I(+)TRAF6, and bta-miR-24-3p mimics were cloned separately in BEECS, and the evaluation of cell viability was done using the CCK-8 assay kit. (C) pcDNA3.I empty vector and pcDNA3.I (+)TRAF6 were cloned separately in BEECS. The cells were harvested to verify transfection efficiency using the RT-qPCR techniques (D) pcDNA3.I empty vector, pcDNA3.I empty vector and LPS, pcDNA3.I (+)TRAF6, and pcDNA3.I(+)TRAF6 and bta-miR-24-3p mimics were cloned separately in BEECS, the cells were harvested to verify the effect of bta-miR-24-3p mimics using the qRT-PCR method. (E) The Bta-miR-24-3p mimic was cotransfected with cloned TRAF6 into BEECs, expressing mRNA level of the pro-inflammatory cytokines (IL-I $\beta$, IL-6, IL-8, and TNF- $\alpha$ ) were measured using qRT-PCR. Data are revealed as mean \pm SD of three independent experiments. ${ }^{* *} p<0.01$ (Student's $t$-test). Abbreviation: Ns, not significant. 


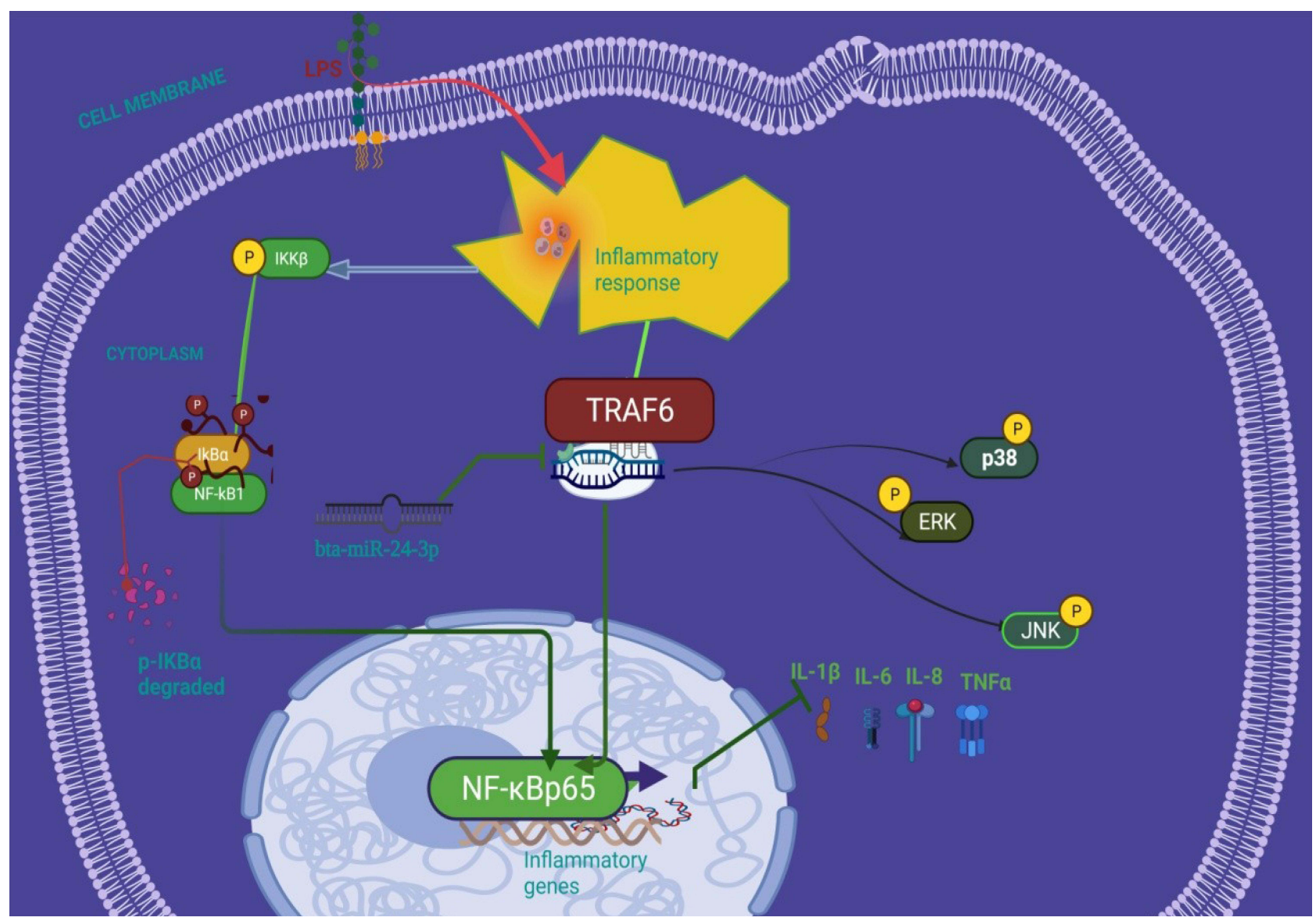

Figure 7 Schematic representation of the anti-inflammatory effect of bta-miR-24-3p suppressing NF-kB/ MAPK signal transduction pathways in LPS-triggered bovine endometrial epithelial cells targeting TRAF6.

\section{Discussion}

The molecular events that lead to the development, progression and resolution of Endometritis are critical in evaluating its pathophysiology; ${ }^{45}$ however, understanding how these molecular events are regulated will contribute to identifying molecular markers and therapeutic strategies that can be used to resolve ongoing inflammation postpartum endometrium in dairy cows. ${ }^{46}$ The establishment and development of Endometritis depend partly on the balance of host defensive response and bacterial species. ${ }^{4-9}$ LPS is the main component of Gram-negative bacteria cell walls, and LPS-induced Endometritis or uterine injury exhibits severe endometrial damage. ${ }^{7,11}$ It is thus used to mimic these uterine disorders to evaluate the possible protection in vivo. ${ }^{8,11,23}$ MiRNAs affect the transcription and translation of target genes by acting on their targeted mRNA. ${ }^{47}$ Many microRNAs have been implicated in endometritis pathogenesis in a quest to resolve the dairy industry menace, ${ }^{32,48}$ including miR-24. In this research, the stable transcript of miR-24 was used to evaluate its role in Endometritis. Bta-miR-24-3p inhibits proliferation and promotes myogenic differentiation of progenitor cells in Fetal Bovine Skeletal Muscle. ${ }^{34}$ MiR-24-3p protects against myocardial ischemia and reperfusion injury by being a cardioprotective factor. ${ }^{35}$ MiR-24 inhibits the proliferation and migration of vascular endothelial cells by deactivating the NF-KB signaling pathway, regulating inflammation in endothelial cells, and preventing the NF-KB signaling pathway in atherosclerosis. ${ }^{36}$ In LPS-challenged neonatal rats, miR-24 overexpression reduced lung inflammation ${ }^{37}$ and disrupted the inflammatory pathway. ${ }^{38}$ In addition, some microRNA such as miR-19a, ${ }^{49}$ miR-148a, ${ }^{50}$ miR-223, ${ }^{51}$ and others have been reported to attenuate the inflammatory effect of LPS on endometrial cells through various signaling pathways and receptors.

Interestingly, our present study found that miR-24-3p expression was dramatically reduced with elevated expression of TRAF6 in LPS-stimulated BEECs and mice uterus, further suggesting that miR-24-3p possessed an imperative role in 
the pathogenesis of Endometritis; this was related to previous studies with other microRNA, ${ }^{19,48}$ although the underlining mechanism remains an enigma. It has been widely accepted that the overproduction of pro-inflammatory mediators, including TNF- $\alpha$, IL-6, IL-8, IL-1 $\beta$, can be harmful and result in various inflammatory diseases. ${ }^{41,43}$ Previous studies showed that treatment of BEECs with ultrapure LPS led to an inflammatory response characterized by increased IL-6, IL8 , IL- $1 \beta$, and TNF- $\alpha$, mRNA expression and concentration. ${ }^{22,23,49-51}$ Similarly, our results showed upregulated mRNA expression of IL-6, IL-8, IL-1 $\beta$, and TNF- $\alpha$ after LPS treatment.

MiR-24-3p mimics were used to increase the expression level of endogenous miR-24-3p to further investigate the function of miR-24-3p. The overexpression of miR-24-3p significantly reduced the expression levels of inflammatory cytokines, including IL-6, IL-8, IL-1 $\beta$, and TNF- $\alpha$. The NF-KB and MAPK signaling has been associated with LPS-induced inflammatory response. ${ }^{22,41,52}$ However, we observed that overexpression of miR-24-3p markedly decreased the protein levels of TRAF6, p-IKB $\alpha$, p-p65 p-p38, p-ERK, and p-JNK in LPS-stimulated BEECs. On the other hand, bioinformatics predictions performed using available miRNA databases (TargetScan 7.2) implied that TRAF6 is a potential molecular target of miR-24-3p. The luciferase reporter assay was carried out in subsequent studies to test the prediction. A notable decrease of luciferase activity upon miR-24-3p transfection was found, manifesting that TRAF6 is an actual target molecule of miR-24$3 p$. Some bovine miRNAs, such as miR-24-3p, have been shown to negatively regulate the TRAF6- mediated inflammatory reaction in vitro. Our study with transfection of miR-24-3p mimic showed that decreased phosphorylation levels of NF- $\mathrm{kB}$ p65 were accompanied by elevated miR-24-3p in LPS-induced BEECs; however, signaling of NF-kB/MAPK was downregulated by the miR-24-3p expression significantly. Our results showed that miR-24-3p attenuated the production and the deactivation of the canonical NF- $\mathrm{kB}$ pathway. That is, activation of intracellular miR-24-3p levels, which, when they reached a certain level, inhibited NF- $\kappa B$ activity and impaired inflammatory processes. Although there was direct evidence in this study that miR-24-3p inhibited the activation of NF- $\mathrm{KB} / \mathrm{MAPK}$, miR-24-3p expression may be spatiotemporally dependent on NF-KB/ MAPK activity. Moreover, knockdown expression of the TRAF6 gene was inhibited by si-TRAF6 and verified the intimate anti-inflammatory relationship between miR-24-3p and TRAF6. Our results showed that silencing of the TRAF6 gene attenuated LPS-mediated inflammation and significantly decreased IKB $\alpha$, p65, p38, ERK, and JNK phosphorylation. The collections of the above results sufficiently demonstrate that TRAF6 is a direct target of miR-24-3p in LPS-induced inflammatory responses with attenuation of NF- $\mathrm{KB} / \mathrm{MAPK}$ signaling pathway. Overall, these results strongly suggested miR$24-3 p$ as an essential negative regulator of TRAF6, leading to the attenuation of LPS-triggered inflammatory response.

\section{Conclusion}

In summary, we first demonstrate that miR-24-3p/TRAF6 molecular interaction plays a vital role in regulating endometrial inflammation at the molecular and cellular levels. Overexpression of miR-24-3p attenuates inflammation via suppressing TRAF6 through deactivation of NF-KB/MAPK signaling pathways. The cellular and molecular differential expression profile of miR-24-3p and TRAF6 in inflamed uterine lesions and BEECs may provide a promising biomarker for the pharmacological discovery of a viable therapeutic regimen against endometritis and other inflammatory diseases. Therefore, a future novel therapeutic modality for miR-24-3p could be employed against inflammation.

\section{Acknowledgments}

We specially thank the sponsor of the research for financial provision.

\section{Funding}

The research was financed by the National Key Research and Development Program of China (2017YFD0502200) and the Science and Technology Innovation Project of CAAS (CAAS-ASTIP-2014LIHPS-03).

\section{Disclosure}

The authors report no conflicts of interest in this work. 


\section{References}

1. Gilbert RO. The effects of endometritis on the establishment of pregnancy in cattle. Reprod Fertil Dev. 2012;24(1):252. doi:10.1071/rd11915

2. LeBlanc SJ. Postpartum uterine disease and dairy herd reproductive performance: a review. Vet J. 2008;176(1):102-114. doi:10.1016/j. tvj1.2007.12.019

3. Sheldon IM, Williams EJ, Miller AN, Nash DM, Herath S. Uterine diseases in cattle after parturition. Vet J. 2008;176:115-121. doi:10.1016/j. tvj1.2007.12.031

4. Potter T, Guitian J, Fishwick J, Gordon PJ, Sheldon IM. Risk factors for clinical endometritis in postpartum dairy cattle. Theriogenology. 2010;74:127-134. doi:10.1016/j.theriogenology.2010.01.023

5. Gilbert RO, Shin ST, Guard CL, Erb HN, Frajblat M. Prevalence of endometritis and its effects on reproductive performance of dairy cows. Theriogenology. 2005;64:1879-1888. doi:10.1016/j.theriogenology.2005.04.022

6. Minten MA, Bilby TR, Bruno RGS, et al. Effects of fertility on gene expression and function of the bovine endometrium. PLoS One. $2013 ; 8: 1-14$. doi:10.1371/journal.pone.0069444

7. Oguejiofor CF, Cheng Z, Abudureyimu A, Fouladi-Nashta AA, Wathes DC. Global transcriptomic profiling of bovine endometrial immune response in vitro. I. Effect of lipopolysaccharide on innate immunity. Biol Reprod. 2015;93(4):100. PMID: 26353891. doi:10.1095/ biolreprod.115.128868

8. Granot I, Gnainsky Y, Dekel N. Endometrial inflammation and effect on implantation improvement and pregnancy outcome. Reproduction. 2012;144(6):661-668. PMID: 23028125. doi:10.1530/REP-12-0217

9. Yongzhi G, Tom VS, Jhamat N, et al. Differential gene expression in bovine endometrial epithelial cells after challenge with LPS; specific implications for genes involved in embryo maternal interactions. PLoS One. 2019;6:1-23.

10. James G, Cronin ML, Turner LG, Clare E, Bryant I, Sheldon ML. Toll-like receptor 4 and MYD88-dependent signaling mechanisms of the innate immune system are essential for the response to lipopolysaccharide by epithelial and stromal cells of the bovine endometrium. Biol Reprod. 2012;86:251-259. doi:10.1095/biolreprod.111.092718

11. Fu Y, Liu B, Feng X, et al. Lipopolysaccharide increases Toll-like receptor 4 and downstream Toll-like receptor signaling molecules expression in bovine endometrial epithelial cells. Vet Immunol Immunopathol. 2013;151(1-2):20-27. doi:10.1016/j.vetimm.2012.09.039

12. Kannaki TR, Shanmugam M, Verma PC. Toll-like receptors and their role in animal reproduction. Anim Reprod Sci. 2011;125(1-4):1-12. doi:10.1016/j.anireprosci.2011.03

13. Keating SE, Maloney GM, Moran EM, Bowie AG. IRAK-2 participates in multiple Toll-like receptor signaling pathways to NFkappaB via activation of TRAF6 ubiquitination. $J$ Biol Chem. 2007;282:33435-33443. doi:10.1074/jbc.M705266200

14. Liu K, Chen K, Zhang Q, et al. TRAF6 neddylation drives inflammatory arthritis by increasing NF- kappa B activation. Lab Invest. 2019;99:528-538. doi:10.1038/s41374-018-0175-8

15. Cui Y, Wang Y, Zhao D, Feng X, Zhang L, Liu C. Loganin prevents BV-2 microglia cells from A $\beta 1-42$-induced inflammation via regulating TLR4/ TRAF6/NF-kappaB axis. Cell Biol Int. 2018;42:1632-1642. doi:10.1002/cbin.11060

16. Park H, Huang X, Lu C, Cairo MS, Zhou X. MicroRNA-146a and MicroRNA-146b regulate human dendritic cell apoptosis and cytokine production by targeting TRAF6 and IRAK1 proteins. J Biol Chem. 2015;290:2831-2841. doi:10.1074/jbc.M114.591420

17. Walsh MC, Lee J, Choi Y. Tumor necrosis factor receptor-associated factor 6 (TRAF6) regulations of development, function, and homeostasis of the immune system. Immunol Rev. 2015;266:72-92. doi:10.1111/imr.12302

18. Tang L, Li X, Bai Y, Wang P, Zhao Y. MicroRNA-146a negatively regulates the inflammatory response to Porphyromonas gingivalis in human periodontal ligament fibroblasts via TRAF6/p38 pathway. J Periodontol. 2019;90:391-399. doi:10.1002/JPER.18-0190

19. Wu H, Fan H, Shou $\mathrm{Z}$, et al. Extracellular vesicles containing miR-146a attenuates experimental colitis by targeting TRAF6 and IRAK1. Int Immunopharmacol. 2019;68:204-212. doi:10.1016/j.intimp.2018.12.043

20. Ma J, Li YT, Zhang SX, Fu SZ, Ye XZ. MiR-590-3p attenuates acute kidney injury by inhibiting tumor necrosis factor receptor-associated factor 6 in septic mice. Inflammation. 2019;42:637-649. doi:10.1007/s10753-018-0921-5

21. Tang X, Zhang L, Wei W. Roles of TRAFs in NF-kappaB signaling pathways mediated by BAFF. Immunol Lett. 2018;196:113-118. doi:10.1016/j. imlet.2018.01.010

22. Dong J, Qu Y, Li J, Cui L, Wang Y, Lin J. Cortisol inhibits NF-кB and MAPK pathways in LPS activated bovine endometrial epithelial cells. Int Immunopharmacol. 2018;56:71-77. doi:10.1016/j.intimp.2018.01.021

23. Wu H, Zhao G, Jiang K, Li C, Qiu C, Deng G. Engeletin alleviates lipopolysaccharide-induced endometritis in mice by inhibiting TLR4-mediated NF-kappaB activation. J Agric Food Chem. 2016;64:6171-6178. doi:10.1021/acs.jafc.6b02304

24. Risco A, Cuenda A. New Insights into the p38 $\gamma$ and p38 $\delta$ MAPK pathways. J Signal Transduct. 2012;1-8. doi:10.1155/2012/520289

25. Cuevas BD, Abell AN, Johnson GL. Role of mitogen-activated protein kinases in signal integration. Oncogene. 2007;26(22):3159-3171. doi:10.1038/sj.onc. 1210409

26. Slattery ML, Mullany LE, Sakoda LC, Wolff RK, Samowitz WS, Herrick JS. The MAPK-signaling pathway in colorectal cancer: dysregulated genes and their association with microRNAs. Cancer Inform. 2018;17:117693511876652. doi:10.1177/1176935118766522

27. Youn GS, Lee KW, Choi S, Park J. Overexpression of HDAC6 induces pro-inflammatory responses by regulating ROS-MAPK-NF- $\mathrm{kB} / \mathrm{AP}-1$ signaling pathways in macrophages. Free Radic Biol Med. 2016;97:14-23. doi:10.1016/j.freeradbiomed.2016.05.014

28. Arthur JSC, Ley SC. Mitogen-activated protein kinases in innate immunity. Nat Rev Immunol. 2013;13:679-692. doi:10.1038/nri3495

29. Dong C, Davis RJ, Flavell RA. MAP kinases in the immune response. Annu Rev Immunol. 2002;20:55-72. doi:10.1146/annurev. immunol.20.091301.131133

30. Bartel DP. MicroRNAs: genomics, biogenesis, mechanism, and function. Cell. 2004;116:281-297. doi:10.1016/S0092-8674(04)00045-5

31. Chekulaeva M, Filipowicz W. Mechanisms of miRNA-mediated post-transcriptional regulation in animal cells. Curr Opin Cell Biol. 2009;21:452-460. doi:10.1016/j.ceb.2009.04.009

32. Ambros V. The functions of animal microRNAs. Nature. 2004;431:350-355. doi:10.1038/nature02871

33. Valinezhad Orang A, Safaralizadeh R, Kazemzadeh-Bavili M. Mechanisms of miRNA-mediated gene regulation from common downregulation to mRNA-specific upregulation. Int J Genomics. 2014;2014:970607. doi:10.1155/2014/970607 
34. Hu X, Xing Y, Ren L, et al. Bta-miR-24-3p controls the myogenic differentiation and proliferation of fetal bovine skeletal muscle-derived progenitor cells by targeting ACVR1B. Animals. 2019;9:859. doi:10.3390/ani9110859

35. Tan H, Qi J, Fan BY, Zhang J, Su FF, Wang HT. MicroRNA-24-3p attenuates myocardial ischemia/reperfusion injury by suppressing RIPK1 expression in mice. Cell Physiol Biochem. 2018;51:46-62. doi:10.1159/000495161

36. Zheng Y, Li Y, Liu G, Qi X, Cao X. MicroRNA-24 inhibits the proliferation and migration of endothelial cells in patients with atherosclerosis by targeting importin- $\alpha 3$ and regulating inflammatory responses. Exp Ther Med. 2018;15:338-344. doi:10.3892/etm.2017.5355

37. Lin Y, Yang Y. MiR-24 inhibits inflammatory responses in LPS-induced acute lung injury of neonatal rats through targeting NLRP3. Pathol Res Pract. 2019;215:683-688. doi:10.1016/j.prp.2018.12.028

38. Sun Q, Zhang Y, Yang G, et al. Transforming growth factor-beta-regulated miR-24 promotes skeletal muscle differentiation. Nucleic Acids Res. 2008;36:2690-2699. doi:10.1093/nar/gkn032

39. Zhao R, Wang J, Zhang X, Chen Y. MiR-643 inhibits lipopolysaccharide-induced endometritis progression by targeting TRAF6. Cell Biol Int. 2020;44(4):1059-1067. doi:10.1002/cbin.1130

40. Hou J, Wang P, Li L, et al. MicroRNA-146a feedback inhibits RIG-I-dependent type I IFN production in macrophages by targeting TRAF6, IRAK1, and IRAK2. J Immunol. 2009;183:2150-2158. doi:10.4049/jimmunol.0900707

41. Wang XP, Luoreng ZM, Zan LS, Li F, Li N. Bovine miR-146a regulates inflammatory cytokines of bovine mammary epithelial cells via targeting the TRAF6 gene. J Dairy Sci. 2017;100:7648-7658. doi:10.3168/jds.2017-12630

42. Zhang LH, Xiao B, Zhong M, et al. LncRNA NEAT1 accelerates renal mesangial cell injury via modulating the miR-146b/TRAF6/NF- $\mathrm{BB}$ axis in lupus nephritis. Cell Tissue Res. 2020;382:627-638. doi:10.1007/s00441-020-03248-z

43. Li Y, Wang D, Wu X, et al. Decreasing of S100A4 in bovine endometritis in vivo and in vitro. Theriogenology. 2020;153:68-73. doi:10.1016/j. theriogenology.2020.05.015

44. Livak KJ, Schmittgen TD. Analysis of relative gene expression data using real-time quantitative PCR and the $2-\Delta \Delta C T$ method. Methods. 2001;25 (4):402-408. doi:10.1006/meth.2001.1262

45. Oladejo AO, Li Y, Wu X, et al. Modulation of bovine endometrial cell receptors and signaling pathways as a nanotherapeutic exploration against dairy cow postpartum endometritis. Animals. 2021;11(6):1516. doi:10.3390/ani11061516

46. Oladejo AO, $\mathrm{Li} \mathrm{Y,} \mathrm{Wu} \mathrm{X,} \mathrm{et} \mathrm{al.} \mathrm{MicroRNAome:} \mathrm{potential} \mathrm{and} \mathrm{veritable} \mathrm{immunomolecular} \mathrm{therapeutic} \mathrm{and} \mathrm{diagnostic} \mathrm{baseline} \mathrm{for} \mathrm{lingering} \mathrm{bovine}$ endometritis. Front Vet Sci. 2020;7:614054. doi:10.3389/fvets.2020.614054

47. Fabian MR, Sonenberg N, Filipowicz W. Regulation of mRNA translation and stability by microRNAs. Annu Rev Biochem. 2010;79:351-379. doi:10.1146/annurev-biochem-060308-103103

48. Hailemariam D, Ibrahim S, Hoelker M, et al. MicroRNA-regulated molecular mechanism underlying bovine subclinical endometritis. Reprod Fertile Dev. 2014;26:898-913. doi:10.1071/rd13027

49. Yin N, Yang Y, Wang X, et al. MiR-19a mediates the negative regulation of the NF-kB pathway in lipopolysaccharide-induced endometritis by targeting TBK1. Inflamm Res. 2019;68:231-240. doi:10.1007/s00011-019-01213-3

50. Jiang K, Yang J, Yang C, et al. miR-148a suppresses inflammation in lipopolysaccharide-induced endometritis. J Cell Mol Med. 2020;24:405-417. doi:10.1111/jcmm.14744

51. Zhao G, Jiang K, Yang Y, et al. The potential therapeutic role of mir-223 in bovine endometritis by targeting the NLRP3 inflammasome. Front Immunol. 2018;9:1-13. doi:10.3389/fimmu.2018.01916

52. Shen Y, Liu B, Mao W, et al. PGE2 downregulates LPS-induced inflammatory responses via the TLR4-NF- $\mathrm{kB}$ signaling pathway in bovine endometrial epithelial cells. Prostaglandins Leukot Essent Fat Acids. 2018;129:25-31. doi:10.1016/j.plefa.2018.01.004

Journal of Inflammation Research

Dovepress

\section{Publish your work in this journal}

The Journal of Inflammation Research is an international, peer-reviewed open-access journal that welcomes laboratory and clinical findings on the molecular basis, cell biology and pharmacology of inflammation including original research, reviews, symposium reports, hypothesis formation and commentaries on: acute/chronic inflammation; mediators of inflammation; cellular processes; molecular mechanisms; pharmacology and novel anti-inflammatory drugs; clinical conditions involving inflammation. The manuscript management system is completely online and includes a very quick and fair peer-review system. Visit http://www.dovepress.com/testimonials.php to read real quotes from published authors.

Submit your manuscript here: https://www.dovepress.com/journal-of-inflammation-research-journal 